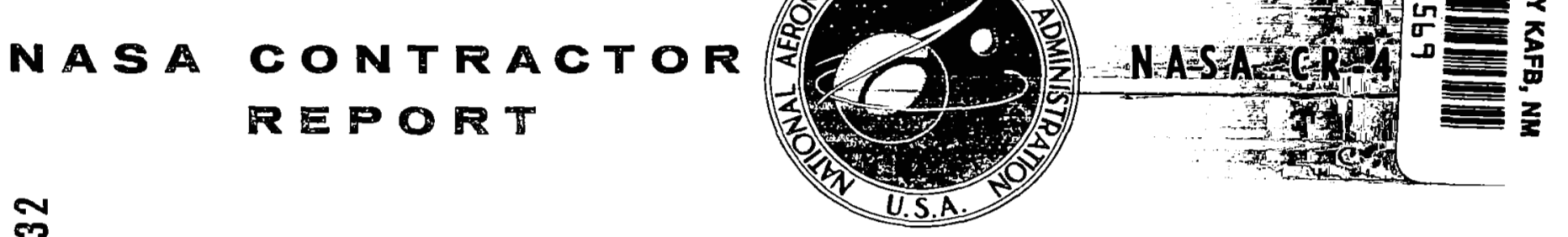

\title{
INFLUENCE OF IMPERFECTIONS AND EDGE RESTRAINT ON THE BUCKLING OF AXIALLY COMPRESSED CYLINDERS
}

\section{by B. O. Almroth}

Prepared under Contract No. NAS 1-3778 by

LOCKHEED MISSILES AND SPACE COMPANY

Sunnyvale, Calif.

for Langley Research Center

NATIONAL AERONAUTICS AND SPACE ADMINISTRATION - WASHINGTON, D. C. • APRIL 1966 
INFLUENCE OF IMPERFECTIONS AND EDGE RESTRAINT ON THE BUCKLING OF AXIALLY COMPRESSED CYLINDERS

By B. O. Almroth

Distribution of this report is provided in the interest of information exchange. Responsibility for the contents resides in the author or organization that prepared it.

Prepared under Contract No. NAS 1-3778 by LOCKHEED MISSILES AND SPACE COMPANY Sunnyvale, Calif.

for Langley Research Center

NATIONAL AERONAUTICS AND SPACE ADMINISTRATION

For sale by the Clearinghouse for Federal Scientific and Technical Information Springfield, Virginia 22151 - Price $\$ 0.85$ 
CONTENTS

Page

SUMMARY

vi

NOTATION

vii

INTRODUCTION

BASIC EQUATIONS

4

PRE BUCKLING DISPLACE MENTS

BUCKLING ANALYSIS

11

RESULTS

14

Perfect Cylinders

14

Cylinders With Imperfections

16

REFERENCES 


\section{ILLUSTRATIONS}

Figure

Page

$1 \quad$ Buckling of Cylinders With Free Edges

2a Critical Loads of Cylinders With Elastic Tangential Restraint:

$\mathrm{r} / \mathrm{t}=100, \mathrm{~L} / \mathrm{r}=0.7$

2b Critical Loads of Cylinders With Elastic Tangential Restraint:

$\mathrm{r} / \mathrm{t}=100, \mathrm{~L} / \mathrm{r}=2.2$

2c Critical Loads of Cylinders With Elastic Tangential Restraint:

$\mathrm{r} / \mathrm{t}=1000, \mathrm{~L} / \mathrm{r}=0.222$

2d Critical Loads of Cylinders With Elastic Tangential Restraint:

$\mathrm{r} / \mathrm{t}=1000, \mathrm{~L} / \mathrm{r}=0.76$

3a Critical Loads for Cylinders With Elastic Rotational Edge

Restraint: $\mathrm{r} / \mathrm{t}=100, \mathrm{~L} / \mathrm{r}=0.7$

3b Critical Loads for Cylinders With Elastic Rotational Edge

Restraint: $\mathrm{r} / \mathrm{t}=100, \mathrm{~L} / \mathrm{r}=2.4$

3c Critical Loads for Cylinders With Elastic Rotational Edge Restraint: $\mathrm{r} / \mathrm{t}=1000, \mathrm{~L} / \mathrm{r}=0.222$

3d Critical Loads for Cylinders With Elastic Rotational Edge Restraint: $\mathrm{r} / \mathrm{t}=1000, \mathrm{~L} / \mathrm{r}=0.76$

4a Critical Loads for Cylinders With Elastic Radial Edge Restraint: $\mathrm{r} / \mathrm{t}=100, \mathrm{~L} / \mathrm{r}=0.7$

4b Critical Loads for Cylinders With Elastic Radial Edge Restraint: $\mathrm{r} / \mathrm{t}=100, \mathrm{~L} / \mathrm{r}=2.4$

4c Critical Loads for Cylinders With Elastic Radial Edge Restraint: $\mathrm{r} / \mathrm{t}=1000, \mathrm{~L} / \mathrm{r}=0.222$

$4 \mathrm{~d}$ Critical Loads for Cylinders With Elastic Radial Edge Restraint: $\mathrm{r} / \mathrm{t}=1000, \mathrm{~L} / \mathrm{r}=0.76$

Variation of Critical Load With Wave Number

6 Critical Load of Cylinder With Supported End Ring. (Torsional stiffness of ring is omitted.) 
9 Buckling Mode for Cylinder With the Edges Free in the Tangential Direction

10 Buckling Modes for Cylinders With End Ring

11 Buckling Modes for Imperfect Cylinders

12 Buckling of Long Cylinders With Periodic Initial Imperfections of Amplitude $\mu \mathrm{t}$

14 Influence of Shape of Initial Imperfection on Critical Load

15 Influence of Initial Imperfections on Cylinder With $\mathrm{N}_{\mathrm{xy}}=0$

17 Influence of Initial Imperfections on Buckling Load of Short Cylinders 


\section{SUMMARY}

Recent investigations on the influence of edge conditions on the critical axial load of cylindrical shells are extended here to include cylinders with elastic edge restraint. It is shown that weak edge conditions are unlikely to affect the critical load significantly in experiments or in practice. Also the effects of symmetric initial imperfections were investigated. The critical load for cylinders with initial imperfections in the form of a cosine function was found to be somewhat lower than was indicated in a previous analysis by Koiter. The analysis also disclosed that very short cylinders would not be sensitive to the types of imperfections which were considered. A few tests were performed and their results tend to support this conclusion. 


\section{NOTATION}

$$
A_{1}, A_{2}
$$

D

E

$\mathrm{F}$

$\mathrm{F}_{\mathrm{i}}$

H

L

M

$M_{x}, M_{y}, M_{x y}, M_{y x}$ $\mathrm{N}$

$\overline{\mathrm{N}}$

$\mathrm{N}_{x}, \mathrm{~N}_{\mathrm{y}}, \mathrm{N}_{\mathrm{xy}}$

$\left(\mathrm{N}_{\mathrm{X}}\right)_{\mathrm{O}}$

$\mathrm{P}_{\mathrm{CR}}$

$\mathrm{W}$

$\mathrm{w}_{\mathrm{i}}$

$\mathrm{Z}$

$a_{1}$

$\mathrm{a}_{2}$

b integration constants

$E t^{3} /\left[12\left(1-\nu^{2}\right)\right]$

Young's modulus

stress function [See Eq. (21)]

values of $F$ at discrete point

radial force at shell edge [See Eq. (6)]

shell length

total number of discrete points

bending and twisting moments per unit width

compressive axial load per unit width

$\mathrm{N} /(2 \gamma \mathrm{Et})$

normal and shear forces per unit width

value of $\mathrm{N}_{\mathrm{x}}$ in prebuckling range

critical axial load on cylinder

lateral displacement [See Eq. (21)]

value of $W$ at discrete point

$\mathrm{L}^{2}\left(1-\nu^{2}\right)^{1 / 2} /(\mathrm{rt})$

$\mathrm{k}(1+\overline{\mathrm{N}})^{1 / 2}$

$k(1-\bar{N})^{1 / 2}$

length of initial imperfection wave [See Eq. (34)] 


\begin{tabular}{|c|c|}
\hline$b_{i}$ & coefficients [See Eq. (19)] \\
\hline c & end ring area divided by $t^{2}$ \\
\hline $\mathbf{c}_{\mathbf{i}}$ & coefficient in displacement function [See Eq. (29)] \\
\hline$d_{i}$ & coefficients [See Eq. (18)] \\
\hline$e_{i}$ & coefficients [See Eq. (20)] \\
\hline $\mathbf{f}$ & stress function \\
\hline $\mathrm{h}$ & distance between neighboring discrete points \\
\hline$i, m, q$ & integers \\
\hline $\mathrm{k}$ & $(2 \gamma)^{-1 / 2}$ \\
\hline $\mathrm{n}$ & number of waves in circumferential direction \\
\hline $\mathrm{p}$ & internal pressure \\
\hline$\overline{\mathrm{p}}$ & $(\mathrm{pr}) /(\mathrm{Et})$ \\
\hline $\mathbf{r}$ & shell radius \\
\hline $\mathrm{t}$ & shell thickness \\
\hline$u, v, w$ & axial, circumferential, and radial displacements \\
\hline $\mathrm{w}_{\mathrm{o}}$ & value of $w$ in prebuckling range \\
\hline$\overline{\mathrm{w}}$ & initial displacement \\
\hline $\overrightarrow{\mathrm{w}}_{1}$ & value of initial displacement [See Eq. (32)] \\
\hline $\mathrm{x}, \mathrm{y}$ & axial and circumferential coordinates \\
\hline$y_{i}$ & value of $\mathrm{F}$ or $\mathrm{W}$ [See Eq. (23)] \\
\hline$\alpha_{1}$ & $\left(a_{1} L\right) /(2 r)$ \\
\hline$\alpha_{2}$ & $\left(\mathrm{a}_{2} \mathrm{~L}\right) /(2 \mathrm{r})$ \\
\hline$\beta_{\mathbf{i}}$ & coefficient in prebuckling displacement [See Eq. (14 \\
\hline 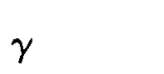 & $(\mathrm{t} / \mathrm{r}) /\left[12\left(1-\nu^{2}\right)\right]^{1 / 2}$ \\
\hline
\end{tabular}


$\Delta$

$\zeta_{\mathbf{i}}$

$\lambda_{\mathrm{ij}}$

$\lambda_{1}, \lambda_{2}, \lambda_{3}$

$\bar{\lambda}_{i}$

$\mu_{\mathrm{i}}$

$\mu$

$\nu$

$\omega$

${ }^{\sigma} \mathrm{CR}$

${ }^{\sigma} \mathrm{CL}$

$\nabla^{4}$ length of initial imperfection wave [See Eq. (32)]

$\mathrm{i} \pi \mathrm{r} / \mathrm{L}$

spring constants [See Eq. (7)]

nondimensional spring constants [See Eq. (8)]

$1 / \lambda_{i}$

nondimensional amplitude of initial displacement component

nondimensional amplitude of sinusoidal initial displacement

Poisson's ratio

initial displacement [See Eqs. $(33,34)]$

critical axial stress

classical value of $\sigma_{\mathrm{CR}}$

$\partial^{4} / \partial x^{4}+2 \partial^{4} / \partial x^{2} \partial y^{2}+\partial^{4} / \partial y^{4}$

When subscripts $\mathrm{x}$ and $\mathrm{y}$ follow a comma, they indicate partial differentiation of the principai variable with respect to $\mathbf{x}$ or $\mathbf{y}$. Primes indicate total derivatives with respect to $x$. 


\section{INTRODUCTION}

Due to the lack of agreement between theory and test, empirical curves, based on a large number of tests, are usually employed in the design of axially compressed cylinders. However, many of the test specimens were probably manufactured poorly and the design curves are generally conservative. Of course, as more test results are made available, questionable test points may be disregarded and better design curves may be constructed. However, the designer will still be on uncertain ground until the buckling problem for the axially loaded cylinder is fully understood. The effects of initial imperfections and of differences in edge conditions, for instance, cannot be satisfactorily evaluated through experimental analysis alone.

The influence of edge conditions as a possible explanation of the discrepancy between theory and test was explored by Nachbar and Hoff (Ref. 1), Stein (Ref. 2), and Fischer (Ref. 3). Nachbar and Hoff considered the case of free edges and found the critical load to be 37 percent of the classical buckling load. Stein presented an analysis of cylinders with supported edges which, for the first time, included an accurate prebuckling analysis. For the particular set of boundary conditions considered by Stein, the computed critical load was about half the classical buckling load. Fischer presented a similar analysis but with different in-plane boundary conditions. Fischer's critical load was as high as 85 percent of the classical buckling load. With boundary conditions identical to those by Stein but with a membrane prebuckling solution Ohira (Ref. 4), Hoff (Ref. 5), and Hoff and Rehfield (Ref. 6) obtained results close to those by Stein. The investigations by Stein and by Fischer were extended by Almroth (Ref. 7) to cover eight different sets of boundary conditions. It was shown that, except in the free edge case, a substantial reduction of the buckling load occurs only when the conditions of simple support and of zero tangential displacement are applied. Neither the case of zero transverse shear force (Nachbar and Hoff) or zero tangential shear 
force (Stein) is likely to be completely realized in tests or in practical applications, but it is possible that considerable reduction may be due to elastic restraint. Therefore, a buckling analysis with elastically supported edges is presented here.

\begin{abstract}
Although weak edge restraint and also disturbances such as accidental lateral loads may be of importance in some practical applications, these factors are certainly of minor importance in tests performed under laboratory conditions. Consequently, the presence of initial geometrical imperfections still appears to be the major reason for the discrepancy between theory and test.
\end{abstract}

Effects of imperfections in the cylinder were investigated by Donnell and Wan (Ref. 8). Their nonlinear analysis demonstrates clearly the importance of the initial imperfections, but, due to the approximations involved, it does not appear possible to use their analysis directly for design purposes.

Some analyses consider cylinders with axially symmetrical initial imperfections only. Koiter (Ref. 9) first presented a general theory which was valid only for imperfections of small amplitude, and later a less restricted theory (Ref. 10). Babcock and Sechler (Ref. 11) derived a solution to the problem which is quite similar to Koiter's latest theory. Both analyses consider only the case in which the initial displacements are described as a simple trigonometric function of the axial coordinate. Babcock and Sechler restricted their analysis to the case in which the axial halfwave length of the initial displacement equals the shell length. Koiter restricted his numerical analysis to include only imperfections which are proportional to the symmetrical buckling pattern of an infinitely long perfect cylinder. Also Fischer (Ref. 3) considered the effect of axially symmetrical initial imperfections. The approach used by Fischer allows more freedom in the choice of the shape of the imperfection. However, numerical results are presented only for one case.

Unless the analysis is restricted to symmetric initial imperfections, the numerical work will require the solution of nonlinear differential equations. Therefore, it is 
reasonable to explore first the symmetrical case fully although such an analysis may not constitute a final solution of the problem. In the present analysis, only axially symmetrical imperfections are considered. The imperfections are represented by trigonometric series, and the effect on the buckling load of imperfection of various shapes is studied. 


\section{BASIC EQUATIONS}

The so-called Donnell equations are used in the present analysis. Thus for a cylinder with an initial imperfection, $\overline{\mathrm{w}}$,

$$
\begin{aligned}
& \mathrm{N}_{\mathrm{x}}=\frac{\mathrm{Et}}{1-\nu^{2}}\left[\left(\mathrm{u}, \mathrm{x}+\frac{1}{2} \mathrm{w}_{, \mathrm{x}}^{2}+\overline{\mathrm{w}}_{, \mathrm{x}} \mathrm{w}_{\mathrm{x}}\right)+\nu\left(\mathrm{v}, \mathrm{y}-\frac{\mathrm{w}}{\mathrm{r}}+\frac{1}{2} \mathrm{w}_{, \mathrm{y}}^{2}+\overline{\mathrm{w}}_{, \mathrm{y}} \mathrm{w}_{\mathrm{y}}\right)\right] \\
& \mathrm{N}_{\mathrm{y}}=\frac{\mathrm{Et}}{1-\nu^{2}}\left[\nu\left(\mathrm{u}, \mathrm{x}+\frac{1}{2} \mathrm{w}_{, \mathrm{x}}^{2}+\overline{\mathrm{w}}_{, \mathrm{x}^{\mathrm{w}}, \mathrm{x}}\right)+\left(\mathrm{v}, \mathrm{y}-\frac{\mathrm{w}}{\mathrm{r}}+\frac{1}{2} \mathrm{w}_{, \mathbf{y}}^{2}+\overline{\mathrm{w}}_{, \mathrm{y}} \mathrm{w}_{\mathrm{y}}\right)\right] \\
& N_{x y}=\frac{E t}{2(1+\nu)}\left[u, y+v, x+v^{\prime}, y^{w}, x+\bar{w}_{, x} w^{w},+\bar{w}, y^{w}, x^{]}\right. \\
& \mathrm{M}_{\mathrm{x}}=-\mathrm{D}(\mathrm{w}, \mathrm{xx}+\nu \mathrm{w}, \mathrm{yy}) \\
& \mathrm{M}_{\mathrm{y}}=-\mathrm{D}(\nu \mathrm{w}, \mathrm{xx}+\mathrm{w}, \mathrm{yy}) \\
& \mathrm{M}_{\mathrm{xy}}=-\mathrm{M}_{\mathrm{yx}}=\mathrm{D}(1-\nu) \mathrm{w}_{, \mathrm{xy}}
\end{aligned}
$$

By use of these equations the total potential energy of the loaded cylinder can be expressed in terms of the displacement components $\mathrm{u}, \mathrm{v}$, and $\mathrm{w}$. From this energy expression we find through the variational approach the three equilibrium equations:

$$
\begin{aligned}
N_{x, x}+N_{x y, y}= & 0 \\
N_{y, y}+N_{x y, x}= & 0 \\
D \nabla^{4} w= & N_{x}\left(\bar{w}_{, x x}+w_{, x x}\right)+N_{y}\left(\bar{w}_{, y y}+w_{, y y}\right) \\
& +2 N_{x y}\left(\bar{w}_{, x y}+w_{, x y}\right)-\frac{1}{r} N_{y}+p
\end{aligned}
$$


An Airy's stress function $f$ is introduced such that

$$
\mathrm{N}_{\mathbf{x}}=\mathbf{f}_{, \mathrm{yy}} ; \mathrm{N}_{\mathbf{y}}=\mathbf{f}_{, \mathbf{x x}} ; \mathrm{N}_{\mathrm{xy}}=-\mathbf{f}_{, \mathrm{xy}}
$$

The first two equations may then be replaced by the compatibility equation

$$
\frac{1}{\mathrm{Et}} \nabla^{4} \mathrm{f}=\mathrm{w}^{2}, \mathrm{xy}-\mathrm{w}, \mathrm{xx} \mathrm{w}^{\mathrm{w}}, \mathrm{yy}+\overline{2 \mathrm{w}}, \mathrm{xy}{ }^{\mathrm{w}}, \mathrm{xy}-\overline{\mathrm{w}}, \mathrm{xx} \mathrm{w}^{\mathrm{w}}, \mathrm{yy}-\overline{\mathrm{w}}, \mathrm{yy}{ }^{\mathrm{w}}, \mathrm{xx}+\frac{1}{\mathrm{r}} \mathrm{w}, \mathrm{xx}
$$

Since the analysis is restricted to axially symmetrical initial imperfections, the equilibrium and compatibility equations may be written as

$$
\left.\begin{array}{l}
\mathrm{D} \nabla^{4} \mathrm{w}=\mathrm{f}, \mathrm{yy}(\overline{\mathrm{w}}, \mathrm{xx}+\mathrm{w}, \mathrm{xx})+\mathrm{f}, \mathrm{xx}{ }^{\mathrm{w}}, \mathrm{yy}-2 \mathrm{f}, \mathrm{xy}{ }^{\mathrm{w}}, \mathrm{xy}-\frac{1}{\mathrm{r}} \mathrm{f}, \mathrm{xx}+\mathrm{p} \\
\frac{1}{\mathrm{Et}} \nabla^{4} \mathrm{f}=\mathrm{w}_{, \mathrm{xy}}^{2}-\mathrm{w}, \mathrm{xx}{ }^{\mathrm{w}}, \mathrm{yy}-\overline{\mathrm{w}}_{, \mathrm{xx}}{ }^{\mathrm{w}}, \mathrm{yy}+\frac{1}{\mathrm{r}} \mathrm{w}, \mathrm{xx}
\end{array}\right\}
$$

In addition to the equilibrium equations, the variational approach yields the following natural boundary conditions at $\mathrm{x}= \pm \mathrm{L} / 2$ :

$$
\begin{aligned}
& f_{, y y}=N_{x}=-N \\
& -\mathbf{f}_{, \mathrm{xy}}=\mathrm{N}_{\mathrm{xy}}=0 \\
& M_{x}=-D(w, x x+\nu w, y y)=0 \\
& H=f_{, y y}(w, x+\bar{w}, x)-f, x y^{w}, y-r^{2}[w, x x x+(2-\nu) w, x y y] E t \gamma^{2}=0
\end{aligned}
$$


All admissible sets of boundary conditions are given by

$$
\begin{aligned}
w & =\lambda_{11} \mathrm{H}+\lambda_{12} \mathrm{M}_{\mathrm{x}}+\lambda_{13} \mathrm{~N}_{\mathrm{xy}}+\lambda_{14} \mathrm{~N}_{\mathrm{x}} \\
\mathrm{w}_{, \mathrm{x}} & =\lambda_{21} \mathrm{H}+\lambda_{22} \mathrm{M}_{\mathrm{x}}+\lambda_{23} \mathrm{~N}_{\mathrm{xy}}+\lambda_{24} \mathrm{~N}_{\mathrm{x}} \\
\mathrm{v} & =\lambda_{31} \mathrm{H}+\lambda_{32} \mathrm{M}_{\mathrm{x}}+\lambda_{33} \mathrm{~N}_{\mathrm{xy}}+\lambda_{34} \mathrm{~N}_{\mathrm{x}} \\
\mathrm{u} & =\lambda_{41} \mathrm{H}+\lambda_{42} \mathrm{M}_{\mathrm{x}}+\lambda_{43} \mathrm{~N}_{\mathrm{xy}}+\lambda_{44} \mathrm{~N}_{\mathrm{x}}
\end{aligned}
$$

It will be sufficient for the purpose of this analysis to consider only the effects of the diagonal terms in Eqs. (7). Consequently in the numerical analysis we assume $\lambda_{i j}=0$ if $i \neq j$. Also, as the choice of boundary condition for loads or displacements in the axial direction generally has little effect on the critical load we will use

$$
\mathrm{N}_{\mathrm{x}}=-\mathrm{N} \text { at } \mathrm{x}= \pm \mathrm{I} / 2
$$

Nondimentional spring constants are defined as follows:

$$
\begin{aligned}
& \lambda_{1}=\lambda_{11} \mathrm{Et} / \mathrm{r} \\
& \lambda_{2}=\lambda_{22} \mathrm{Et}^{2} \\
& \lambda_{3}=\lambda_{33} \mathrm{Et} / \mathrm{r}
\end{aligned}
$$

Thus the boundary conditions may be written (for total displacements)

$$
\begin{aligned}
\mathrm{N}_{\mathrm{x}} & =-\mathrm{N} \\
\mathrm{w}+\lambda_{1}(\mathrm{Hr}) /(\mathrm{Et}) & =0 \\
\mathrm{w}_{, \mathrm{x}}+\lambda_{2} \mathrm{M}_{\mathrm{x}} /\left(\mathrm{Et} \mathrm{t}^{2}\right) & =0 \\
\mathrm{v}-\lambda_{3}\left(\mathrm{~N}_{\mathrm{xy}} \mathrm{r}\right) / \mathrm{Et} & =0
\end{aligned}
$$




\section{PREBUCKLING DISPLACEMENTS}

As only axially symmetric imperfections are included in the analysis the prebuckling displacements will be independent of the circumferential coordinate. Derivatives of prebuckling displacements with respect to $y$ will vanish and from Eqs. (5) we obtain

$$
\left.\begin{array}{rl}
D w_{0, x x x x}+N w_{0, x x}+(1 / r) f_{0, x x}-p & =-N \bar{w}_{, x x} \\
(1 / E t) f_{0, x x x x} & =(1 / r) w_{0, x x}
\end{array}\right\}
$$

where the subscript zero is used to signify prebuckling quantities, $\bar{w}$ represents the initial lateral displacement, and $N=-N_{X}$.

Prebuckling displacements must be symmetric about $\mathrm{x}=0$, and therefore only even functions are included in the solution of the differential equations and the boundary conditions need only be enforced at $\mathrm{x}=+\mathrm{L} / 2$. The homogeneous solution consequently is

$$
\begin{aligned}
w_{0}= & r(2 \nu \gamma \bar{N}+\bar{p})\left[1+A_{1} \sin \left(a_{1} x / r\right) \sinh \left(a_{2} x / r\right)\right. \\
& \left.+A_{2} \cos \left(a_{1} x / r\right) \cosh \left(a_{2} x / r\right)\right]
\end{aligned}
$$

where

$$
\begin{aligned}
\overline{\mathrm{N}} & =\mathrm{N} /(2 \gamma \mathrm{Et}) \\
\overline{\mathrm{p}} & =(\mathrm{pr}) /(\mathrm{Et}) \\
\mathrm{a}_{1} & =\mathrm{k}(1+\overline{\mathrm{N}})^{1 / 2} \\
\mathrm{a}_{2} & =\mathrm{k}(1-\overline{\mathrm{N}})^{1 / 2} \\
\mathrm{k} & =(2 \gamma)^{1 / 2}
\end{aligned}
$$


and $A_{1}, A_{2}$ are constants of integration. It is assumed that the initial displacements may be expressed as a trigonometric series as follows

$$
\bar{w}=\sum_{i=0}^{\infty} t \mu_{i} \cos \left(\frac{i \pi x}{L}\right)
$$

Consequently, Eqs. (10) have a particular solution

$$
\mathrm{w}_{0}=\sum_{\mathrm{i}=0}^{\infty} \beta_{\mathrm{i}} \cos \left(\frac{\zeta_{\mathrm{i}} \mathrm{x}}{\mathrm{r}}\right)
$$

where

$$
\begin{aligned}
& \beta_{i}=\frac{2 \bar{N} \gamma \mu_{i}(t / r) \zeta_{i}^{2}}{1-2 \bar{N} \gamma \zeta_{i}^{2}+\gamma^{2} \zeta_{i}^{4}} \\
& \zeta_{i}=\frac{i \pi r}{L}
\end{aligned}
$$

Due to the existing symmetry only two boundary conditions are needed, the second and third of Eqs. (9). For the case of axial symmetry they may be written

$$
\begin{aligned}
\mathrm{w}_{0}-\mathrm{r} \lambda_{1}\left[2 \gamma \overline{\mathrm{N}}\left(\mathrm{w}_{0, \mathrm{x}}+\overline{\mathrm{w}}_{, \mathrm{x}}\right)+\mathrm{r}^{2} \gamma^{2} \mathrm{w}_{0, \mathrm{xxx}}\right] & =0 \\
\mathrm{w}_{0, \mathrm{x}}-\mathrm{r} \lambda_{2} \mathrm{w}_{0, \mathrm{xx}} & =0
\end{aligned}
$$

By addition of the previously found solution, Eq. (11), and the particular solution, Eq. (14), and substitution of the sum into the boundary conditions, Eq. (15), we find for the prebuckling displacements

$$
\begin{aligned}
\mathrm{w}_{0}= & \mathrm{r}\left(\nu \frac{\mathrm{N}}{\mathrm{E} \mathrm{t}}+\frac{\mathrm{pr}}{\mathrm{Et}}\right)\left[1+\mathrm{A}_{1} \sin \left(\frac{\mathrm{a}_{1} \mathrm{x}}{\mathrm{r}}\right) \sinh \left(\frac{\mathrm{a}_{2} \mathrm{x}}{\mathrm{r}}\right)\right. \\
& \left.+\mathrm{A}_{2} \cos \left(\frac{\mathrm{a}_{1} \mathrm{x}}{\mathrm{r}}\right) \cosh \left(\frac{\mathrm{a}_{1} \mathrm{x}}{\mathrm{r}}\right)\right]+\sum_{\mathrm{i}=0}^{\infty} \beta_{i} \cos \left(\frac{\zeta_{i} \mathbf{x}}{\mathrm{r}}\right)
\end{aligned}
$$


where

$\left.\begin{array}{l}A_{1}=\frac{e_{2} d_{2}-d_{4}\left(d_{5}+e_{1}\right)}{d_{2} d_{3}-d_{1} d_{4}} \\ A_{2}=\frac{d_{3} \cdot\left(e_{1}+d_{5}\right)-d_{1} e_{2}}{d_{2} d_{3}-d_{1} d_{4}}\end{array}\right\}$

$\mathrm{d}_{1}=\mathrm{b}_{1}-\lambda_{1}\left(\gamma^{2} \mathrm{~b}_{7}+2 \gamma \overline{\mathrm{N}} \mathrm{b}_{3}\right)$

$\mathrm{d}_{2}=\mathrm{b}_{2}-\lambda_{1}\left(\gamma^{2} \mathrm{~b}_{8}+2 \gamma \overline{\mathrm{N} \mathrm{b}_{4}}\right)$

$d_{3}=b_{3}-\lambda_{2} \gamma^{2}(r / t) b_{5}$

$\mathrm{d}_{4}=\mathrm{b}_{4}-\lambda_{2} \gamma^{2}(\mathrm{r} / \mathrm{t}) \mathrm{b}_{6}$

$d_{5}=-(2 \nu \gamma \bar{N}+\bar{p})$

$\alpha_{1}=\left(a_{1} L\right) /(2 r)$

$\alpha_{2}=\left(a_{2} L\right) /(2 r)$

$\mathrm{b}_{1}=\sin \alpha_{1} \sinh \alpha_{2}$

$\mathrm{b}_{2}=\cos \alpha_{1} \cosh \alpha_{2}$

$\mathrm{b}_{3}=\mathrm{k}\left[(1-\overline{\mathrm{N}})^{1 / 2} \sin \alpha_{1} \cosh \alpha_{2}+(1+\overline{\mathrm{N}})^{1 / 2} \cos \alpha_{1} \sinh \alpha_{2}\right]$

$\mathrm{b}_{4}=-\mathrm{k}\left[(1+\overline{\mathrm{N}})^{1 / 2} \sin \alpha_{1} \cosh \alpha_{2}-(1-\overline{\mathrm{N}})^{1 / 2} \cos \alpha_{1} \sinh \alpha_{2}\right]$

$b_{5}=-2 k^{2}\left[\bar{N} \sin \alpha_{1} \sinh \alpha_{2}-\left(1-\bar{N}^{2}\right)^{1 / 2} \cos \alpha_{1} \cosh \alpha_{2}\right]$

$\mathbf{b}_{6}=-2 \mathbf{k}^{2}\left[\left(1-\overline{\mathrm{N}}^{2}\right)^{1 / 2} \sin \alpha_{1} \sinh \alpha_{1}+\overline{\mathrm{N}} \cos \alpha_{1} \cosh \alpha_{2}\right]$

$b_{7}=-2 k^{3}\left[(1-\bar{N})^{1 / 2}(1+2 \bar{N}) \sin \alpha_{1} \cosh \alpha_{2}-(1+\bar{N})^{1 / 2}(1-2 \bar{N}) \cos \alpha_{1} \sinh \alpha_{2}\right]$

$\mathrm{b}_{8}=-2 \mathrm{k}^{3}\left[(1+\overline{\mathrm{N}})^{1 / 2}(1-2 \overline{\mathrm{N}}) \sin \alpha_{1} \cosh \alpha_{2}-(1-\overline{\mathrm{N}})^{1 / 2}(1+2 \overline{\mathrm{N}}) \cos \alpha_{1} \sinh \alpha_{2}\right]$ 


$$
\begin{aligned}
e_{1}= & \left\{-w_{0} / r+\lambda_{1}\left[r^{2} \gamma^{2} w_{0, x x x}+2 \gamma \bar{N} w_{0, x}-2 \gamma \overline{\mathrm{N}} \bar{w}_{, x}\right]\right\}_{x=L / 2} \\
= & \frac{1}{r} \sum_{i=0}^{\infty}\left[\beta_{4 i+2}-\beta_{4 i}+\lambda_{1} \gamma^{2}\left(\zeta_{4 i+1}^{3} \beta_{4 i+1}-\zeta_{4 i+3}^{3} \beta_{4 i+3}\right)\right. \\
& \left.\left.+\lambda_{1} 2 \gamma \bar{N}\left\{\zeta_{4 i+1}\left[\beta_{4 i+1}-(t / r) \mu_{4 i+1}\right]-\zeta_{4 i+3}\left[\beta_{4 i+3}-(t / r) \mu_{4 i+3}\right]\right\}\right]\right\} \\
e_{2}= & {\left[-w_{0, x}+r \lambda_{2}(r / t) \gamma^{2} w_{0, x x}\right]_{x=L / 2} } \\
= & \frac{1}{r} \sum_{i=0}^{\infty}\left[\zeta_{4 i+3} \beta_{4 i+3}-\zeta_{4 i+1} \beta_{4 i+1}+\lambda_{2}(r / t) \gamma^{2}\left(\zeta_{4 i}^{2} \beta_{4 i}-\zeta_{4 i+2}^{2} \beta_{4 i+2}\right)\right]
\end{aligned}
$$




\section{BUCKIING ANALYSIS}

Buckling equations are derived from the nonlinear differential equations through decomposition of stresses and displacements into prebuckling and incremental quantities. Then in the resulting equations, the terms containing only prebuckling quantities may be subtracted out by virtue of prebuckling equilibrium, and nonlinear terms in the (infinitesimal) incremental quantities may be disregarded. This procedure results in the replacement of nonlinear equations of equilibrium by linear equations of stability.

The space variables in these equations may be separated by means of the following representation for $\mathbf{f}$ and $\mathbf{w}$ :

$$
\begin{aligned}
f & =F \cos (n y / r) \\
w & =W \cos (n y / r)
\end{aligned}
$$

The problem is thus reduced to the solution of a set of linear ordinary differential equations with variable coefficients. A finite difference approach will be used to effect a numerical solution. The differential equations and the boundary conditions are converted into a system of algebraic equations by use of the following approximations:

$$
\begin{aligned}
y^{\prime} & =\left[y_{i+1}-y_{i-1}\right] /(2 h) \\
y^{\prime \prime} & =\left[y_{i+1}-2 y_{i}+y_{i-1}\right] / h^{2} \\
y_{i}^{\prime \prime \prime} & =\left[1 / 2 y_{i+2}-y_{i+1}+y_{i-1}-1 / 2 y_{i-2}\right] / h^{3} \\
y_{i}^{\prime \prime \prime \prime} & =\left[y_{i+2}-4 y_{i+1}+6 y_{i}-4 y_{i-1}+y_{i-2}\right] / h^{4}
\end{aligned}
$$


The unknowns of the problem are the values of $W$ and $F\left(W_{i}\right.$ and $\left.F_{i}\right)$ at a finite number of points, including the fictitious points outside the cylinder which are needed for definition of the boundary conditions. The points are spaced at a constant distance $h$. The total number of points is $M=L /(2 h)+5$.

The number of unknowns equals $2 \mathrm{M}$. The equilibrium and compatibility equations at each of the real points on the cylinder and the eight boundary conditions provide $2 \mathrm{M}$ equations. For convenience in the numerical analysis, the unknowns $\left(W_{i}\right.$ and $\left.F_{i}\right)$ are denoted by $y_{i}$ such that

$$
\begin{aligned}
\mathrm{y}_{2 \mathrm{~m}} & =\mathrm{w}_{\mathrm{m}} \\
\mathrm{y}_{2 \mathrm{~m}-1} & =\mathrm{F}_{\mathrm{m}}
\end{aligned}
$$

The finite difference equations of equiiibrium and compatibility are identical to Eqs. (31) and (32) of Ref. 7, except that $\left(\mathrm{W}_{\mathrm{o}}^{\prime \prime}\right)_{\mathrm{m}}$ is replaced by $\left(\mathrm{W}_{\mathrm{o}}^{\prime \prime}\right)_{\mathrm{m}}+\overline{\mathrm{W}}_{\mathrm{m}}^{\prime \prime}$. Due to symmetry of loading and boundary conditions, the incremental displacements are either symmetric or antisymmetric about $\mathrm{x}=0$. For the symmetrical case, the boundary conditions at mid-length are given by Eqs. (30) in Ref. 7. In the case of antisymmetry the boundary conditions at $x=0$ are

$$
\begin{aligned}
\mathrm{W} & =0 \\
\mathrm{~W}^{\prime \prime} & =0 \\
\mathrm{~F}^{\prime \prime} & =0 \\
\mathrm{v} & =0
\end{aligned}
$$

It can be shown that the condition $\mathrm{v}=0$ is identical to the condition that $F^{\prime \prime}+\nu \mathrm{n}^{2} \mathrm{~F}=0$. By virtue of the third condition of Eqs. (24), then $\mathrm{v}=0$ can 
here by replaced by $F=0$. In terms of finite differences the boundary conditions for the antisymmetric case are

$$
\begin{aligned}
& \mathrm{w}_{3}=\mathrm{y}_{6} \quad=0 \\
& \left(w^{\prime \prime}\right)_{3}=\left(y_{8}-2 y_{6}+y_{4}\right) / h^{2}=0 \\
& \left(F^{\prime \prime}\right)_{3}=\left(y_{7}-2 y_{5}+y_{3}\right) / h^{2}=0 \\
& \mathrm{~F}_{3}=\mathrm{y}_{5} \quad=0
\end{aligned}
$$

The finite difference expressions for the elastic boundary conditions at the shell edge (Eqs. 9) in terms of finite differences are

$$
\left.\begin{array}{rl}
\left(1 / \mathrm{n}^{2}\right) \mathrm{N}_{\mathrm{x}}= & \mathrm{y}_{2 \mathrm{M}-5}=0 \\
\mathrm{w}+\frac{\mathrm{r}}{\mathrm{Et}} \lambda_{1} \mathrm{H}= & \mathrm{y}_{2 \mathrm{M}-4}-\lambda_{1}\left\{\mathrm{r}\left[2 \gamma \overline{\mathrm{N}}+\gamma^{2}(2-\nu)\right]\left(\mathrm{y}_{2 \mathrm{M}-2}-\mathrm{y}_{2 \mathrm{M}-6}\right) /(2 \mathrm{~h})\right. \\
& \left.+\gamma^{2} \mathrm{r}^{2}\left(\frac{1}{2} \mathrm{y}_{2 \mathrm{M}}-\mathrm{y}_{2 \mathrm{M}-2}+\mathrm{y}_{2 \mathrm{M}-4}-\frac{1}{2} \mathrm{y}_{2 \mathrm{M}-6}\right) / \mathrm{h}^{3}\right\}=0 \\
\mathrm{w}, \mathrm{x}+\frac{1}{\mathrm{Et}^{2}} \lambda_{2} \mathrm{M}_{\mathrm{x}}= & \left(\mathrm{y}_{2 \mathrm{M}-2}-\mathrm{y}_{2 \mathrm{M}-6}\right) /(2 \mathrm{~h}) \\
& -\lambda_{2}(\mathrm{r} / \mathrm{t}) \gamma^{2}\left[\mathrm{r}\left(\mathrm{y}_{2 \mathrm{M}-2}-2 \mathrm{y}_{2 \mathrm{M}-4}+\mathrm{y}_{2 \mathrm{M}-6}\right) / \mathrm{h}^{2}-\frac{\nu \mathrm{n}}{\mathrm{r}} \mathrm{y}_{2 \mathrm{M}-4}\right]=0 \\
\mathrm{v}-\frac{\mathrm{r}}{\mathrm{Et}} \lambda_{3} \mathrm{~N}_{\mathrm{xy}}= & \mathrm{y}_{2 \mathrm{M}-4}-\mathrm{r}^{2}\left(\mathrm{y}_{2 \mathrm{M}-3}-2 \mathrm{y}_{2 \mathrm{M}-5}+\mathrm{y}_{2 \mathrm{M}-7}\right) / \mathrm{h}^{2} \\
& -\nu \mathrm{n}^{2} \mathrm{y}_{2 \mathrm{M}-5}+\lambda_{3} \mathrm{rn}^{2}\left(\mathrm{y}_{2 \mathrm{M}-3}-\mathrm{y}_{2 \mathrm{M}-7}\right) / 2 \mathrm{~h}=0
\end{array}\right\}
$$

The equilibrium and compatibility equations together with these boundary conditions define a linear homogeneous equation system of size $2 \mathrm{M}$. This equation system can have nontrivial solutions only if the determinant of the coefficients equals zero. The lowest value of $\overline{\mathrm{N}}$ for which the determinant vanishes corresponds to the critical load of the cylinder. This value of $\overline{\mathrm{N}}$ will be found by a trial and error method. 


\section{RESULTS}

\section{Perfect cylinders}

Numerical results were obtained from an IBM 7094 digital computer. The accuracy of these results depends on the use of a sufficiently fine mesh size in the finite difference scheme. The investigations of Ref. 7 have essentially established the number of points needed for satisfactory accuracy and therefore the number of points was varied here only in a few check cases.

The limiting cases of complete restraint are obtained if the corresponding non-dimensional spring constants are set equal to zero. In order that free edge conditions could also be included in the analysis, the program was branched such that the inverse of these constants could be used. Complete agreement was found with the results of Ref. 7 . for perfect cylinders in the limiting cases.

Figure 1* shows the variation of the critical load with shell length for the case in which the edges are free in the radial direction. This case was not included in Ref. 7. Results for long shells are available in Ref. 1 for this edge condition. Although the boundary conditions in the two analyses were somewhat different, the numerical results are in good agreement.

Buckling loads for shells with elastic edge restraint are shown in Figs. 2, 3, and 4. The variation of the critical load with the tangential restraint parameter $\lambda_{3}$ is shown in Fig. 2 for different values of the number of circumferential waves. Curves which fall above their neighbors in the entire range are generally not shown in order that the figure be as clear as possible. When the rotational edge restraint $\lambda_{2}$ was varied, it was assumed that the shell was free in the tangential direction as otherwise the spread of the values of the critical load over the $\lambda_{2}$-range would be quite small. The results are shown in Fig. 3. The variation of the critical load with radial edge

*Figures are presented at the end of this section. 
restraint $\lambda_{1}$ is shown in Fig. 4. Only cylinders with $v=0$ are considered because with $N_{x y}=0$ at the edges, the critical load is almost independent of the amount of elastic restraint. From these figures it is seen that the curves for different numbers of waves are sometimes arranged in a disorderly manner. The reason for this is that the critical load as a function of the wave number may have two minima as illustrated in Fig. 5.

The results shown in Figs. 2, 3, and 4 can be used to determine the critical load of a perfect cylinder whenever the stiffness of the substructure is known. In order to facilitate a quantitative understanding of the curves, buckling loads have been computed for cylinders with an end ring. Two different cases have been considered. In the first case, the cylinder edge is supported in the radial direction and the torsional stiffness of the end ring is omitted such that it provides support only against tangential displacement. In the second case, the torsional stiffness of the ring is included but the radial support is removed.

The end ring cross section is assumed to be square. For such a ring with area equal to $\mathrm{ct}^{2}$, the nondimensional elastic constants are

$$
\left.\begin{array}{l}
\bar{\lambda}_{1}=1 / \lambda_{1}=c \frac{\mathrm{t}}{\mathrm{r}}\left(1+\frac{\mathrm{n}^{4} \mathrm{ct}^{2}}{12 \mathrm{r}^{2}}\right) \\
\bar{\lambda}_{2}=1 / \lambda_{2}=\frac{0.141}{2(1+\nu)} \mathrm{c}^{2} \mathrm{n}^{2}\left(\frac{\mathrm{t}}{\mathrm{r}}\right)^{2} \\
\bar{\lambda}_{3}=1 / \lambda_{3}=\mathrm{n}^{2} \mathrm{c}\left(\frac{\mathrm{t}}{\mathrm{r}}\right)
\end{array}\right\}
$$

There is, of course, also a coupling term between tangential and radial displacements but, according to previous assumptions, this term is omitted.

The variation of the critical load with the size of the end ring is shown in Figs. 6 and 7. For the case in which the ring is radially supported (Fig. 6) as well as the case in which the ring is free (Fig. 7), it is seen that a very small ring is sufficient to make the critical load of the shell appproximately equal to the critical load for a shell 
with complete restraint. In both cases the restraint against axial displacements was omitted.

Figures 8, 9, and 10 show buckling modes for cylinders with different boundary conditions.

The mode shape shown in Fig. 8 corresponds to a simply supported cylinder $\mathrm{v}=0$. Parameter values are the same as those considered by Fischer in Ref. 3. Although the critical loads found in the two analyses are identical, there is a slight difference in the mode shapes, inasmuch as the corresponding curve in Ref. 3 appears to have a horizontal tangent at the end of the cylinder. Figure 9 shows the mode shape for a cylinder with the edges free in the tangential direction only. In Fig. 10 is demonstrated how the mode shapes vary with the size of an end ring. The curve with $c=0$ shows the mode shape for a cylinder with free edges and the curve for $c=16$ approximates the mode shape for a clamped cylinder.

Some consideration was given to the question of which boundary conditions are generally applicable in practice. A large number of cylindrical shells constituting structural parts of missiles and spacecraft were studied. In view of the above results for cylinders with end rings, it was concluded that in no case would the critical load of a perfect cylinder be significantly below the critical load for the simply supported cylinder with $\mathrm{v}=0$ and $\mathrm{w}=0$. It is judged that cylinders with extremely weak edge conditions will rarely occur in practice.

\section{Cylinders with imperfections}

Koiter in Ref. 9 gives the critical load of infinitely long cylinders with an initial displacement in the form of a simple trigonometric function. According to this analysis, the critical number of waves is given by

$$
\mathrm{n}^{2}=\frac{1}{2} \sqrt{3\left(1-\nu^{2}\right)}(\mathrm{r} / \mathrm{t}) \quad, \quad(\mu \leq 0.3)
$$


For reasonably long, simply supported shells $\left(\mathrm{N}_{\mathrm{x}}=0, \mathrm{v}=0\right)$, and with this value of $n$, it was found that the numerical results from the present analysis are in good agreement with those by Koiter. However, in the present analysis, lower critical loads were found for other values of $n$. For instance, in the case of a cylinder with $\mathrm{r} / \mathrm{t}=100$ and the amplitude of the imperfection given by $\mu=0.2$, Koiter's analysis as well as the present analysis indicates a critical load equal to 0.447 times the classical buckling load when $n=9$. The lowest buckling load which occurred at $\mathrm{n}=4$ was found to be .389 times the classical buckling load. The mode shapes corresponding to $n=4$ and $n=9$ are shown in Fig. 11. It is interesting to note that with $n=9$, the cylinder has nodes at all points of maximum outward initial displacement. Koiter assumed that the buckled shape could be represented by

$$
w(x, y)=t \sum_{i=1}^{\infty} c_{i} \cos \left[(2 i-1) \frac{q x}{r}\right] \cos \left(\frac{n y}{r}\right)
$$

for the case in which the initial displacement is given by

$$
\overline{\mathrm{w}}(\mathrm{x})=-\mu \mathrm{t} \cos \left(\frac{2 \mathrm{px}}{\mathrm{r}}\right)
$$

This buckling mode is in good agreement with the mode found here for $n=9$ but evidently Koiter's analysis is too restrictive to include the buckling pattern corresponding to $\mathrm{n}=4$. Therefore, Koiter's analysis was modified here, such that the incremental displacements are now represented by

$$
w(x, y)=t \sum_{i=1}^{\infty} c_{i} \cos \left[(2 i-1) \frac{q}{m} \frac{x}{r}\right] \cos \left(\frac{n y}{r}\right)
$$

Koiter's original analysis $(\mathrm{m}=1)$ assumes that nodes in the lateral displacement occur at each point of maximum outward initial displacement. With the modified displacement function, the nodes occur at every $\mathrm{m}^{\text {th }}$ maximum point. The modified formulation was programmed for the digital computer and $m$ was varied to minimize the critical load. The results so obtained were in good agreement with results from the finite difference analysis for reasonably long shells. The program was used also 
to determine the critical load for long cylinders as a function of the amplitude of the initial imperfections. The results, which are valid for all $r / t$ values, are shown by the middle curve in Fig. 12. It was found for $\mu=0.2$ that the critical load has a minimum at $m=9$. This means, of course, that the critical axial wavelength is finite and that, for sufficiently long shells, the finite difference approach, also with $\mathrm{n}=4$, should lead to a nodal buckling pattern. This was shown to be the case for a shell with $\mathrm{L} / \mathrm{r}=8.4$, and the corresponding buckling mode is shown in Fig. 13.

Figure 14 shows some results which were obtained by use of a two-term representation of the initial displacements. It can be seen that with a fixed amplitude, the buckling load is smaller for a more blunt shape of the initial imperfection. It thus appears reasonable to assume that a lower bound to the critical load for cylinders with periodic axially symmetric imperfections of fixed amplitude $\bar{w}$ can be obtained through analysis of the case in which

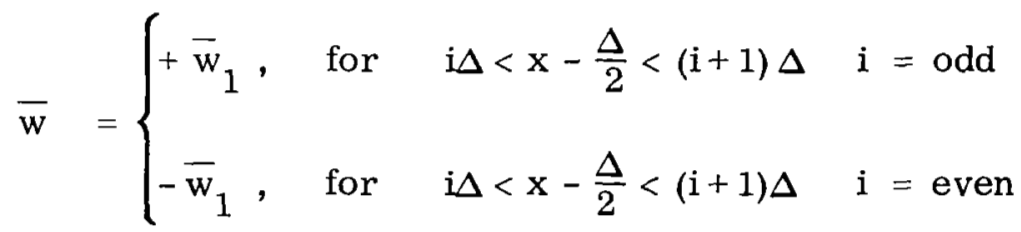

Obviously this discontinuous function does not represent meaningful initial displacements. However, a finite segment of the Fourier series representation of this function is continuous. With increasing number of terms in such a series the corresponding critical load increases monotonically but within a narrow load range. Consequently the critical load based on a one-term series may be considered a reasonably close lower bound to the buckling load of cylinders with periodic initial imperfections of amplitude $\overrightarrow{\mathrm{w}}_{1}$. The amplitude of the first term is about $1.25 \overrightarrow{\mathrm{w}}_{1}$, and the lower bound shown in Fig. 12 can easily be constructed.

For long cylinders with sinusoidally varying initial imperfections results were obtained also with other boundary conditions. Figure 15 shows the critical stress versus amplitude of imperfections for cylinders with the edges free in the tangential direction. Figure 16 shows the corresponding stresses for cylinders with completely free edges. 
It may be seen that the influence of edge conditions on the critical stress diminishes with growing amplitude of initial imperfections.

In Ref. 3 Fischer gave a solution for an initial imperfection of the form

$$
\overline{\mathrm{w}}= \begin{cases}\omega \cos ^{3}(\pi \mathrm{x}) /(2 \mathrm{~b}) & 0 \leq \mathrm{x}<\mathrm{b} \\ 0 & \mathrm{~b} \leq \mathrm{x} \leq \mathrm{L} / 2\end{cases}
$$

Fischer's numerical results indicate that an initial imperfection as described by Eq. (33) is considerably less critical than a periodic imperfection of the same amplitude. However, the numerical analysis was very restricted. Only two values of $b$ were considered and only positive values of $\omega$ were considered, and it appears likely that negative values (inward bulge) should be more critical.

Therefore, the influence of nonperiodic imperfections is investigated here. The form of the imperfection was chosen

$$
\overline{\mathrm{w}}= \begin{cases}\omega \cos ^{2}(\pi \mathrm{x}) /(2 \mathrm{~b}) & 0 \leq \mathrm{x} \leq \mathrm{b} \\ 0 & \mathrm{~b} \leq \mathrm{x} \leq \mathrm{L} / 2\end{cases}
$$

It was found that an imperfection of this type, for all values of $b$, is slightly less harmful than a periodic imperfection with the amplitude $\omega / 2$.

It appears feasible that the lower curve in Fig. 12 really represents a lower bound even if cylinders with nonsymmetric imperfections are included. If this could be shown to be the case by use of suitable experiments or by additional theoretical analysis, then the present results could be made directly useful for the designer. 
Figure 17 shows the influence of initial imperfections on the critical load of cylinders of different lengths. It appears that a sufficiently short cylinder is not sensitive to initial imperfections. A few tests of ring stiffened cylinders have been performed and tend to confirm this conclusion.

The cylinders were manufactured from 0.02 inch aluminum sheet (AL 6061-T8) and rectangular aluminum rings were bonded to the skin as shown in Fig. 18. Three cylinders had outside rings spaced at 1.33 inches and three cylinders inside rings spaced at 1.14 inches. Three cylinders without stiffening were tested for comparison. As the ring-stiffened cylinders are such that buckling between rings is critical the classical buckling load for all three different types of cylinders should be

$$
\mathrm{P}_{\mathrm{CR}}=2 \pi\left[3\left(1-\nu^{2}\right)\right]^{-1 / 2} \mathrm{Et}^{2}
$$

Test results are shown in Table $\mathrm{I}$. The values of $\mathrm{Z}$ given in the table are based on the ring spacing rather than on the shell length. It can be seen from the test results that the ring-stiffened cylinders carry the classical buckling load for monocoque cylinders, hence also the experiment indicates that very short cylinders are not sensitive to initial imperfections. 


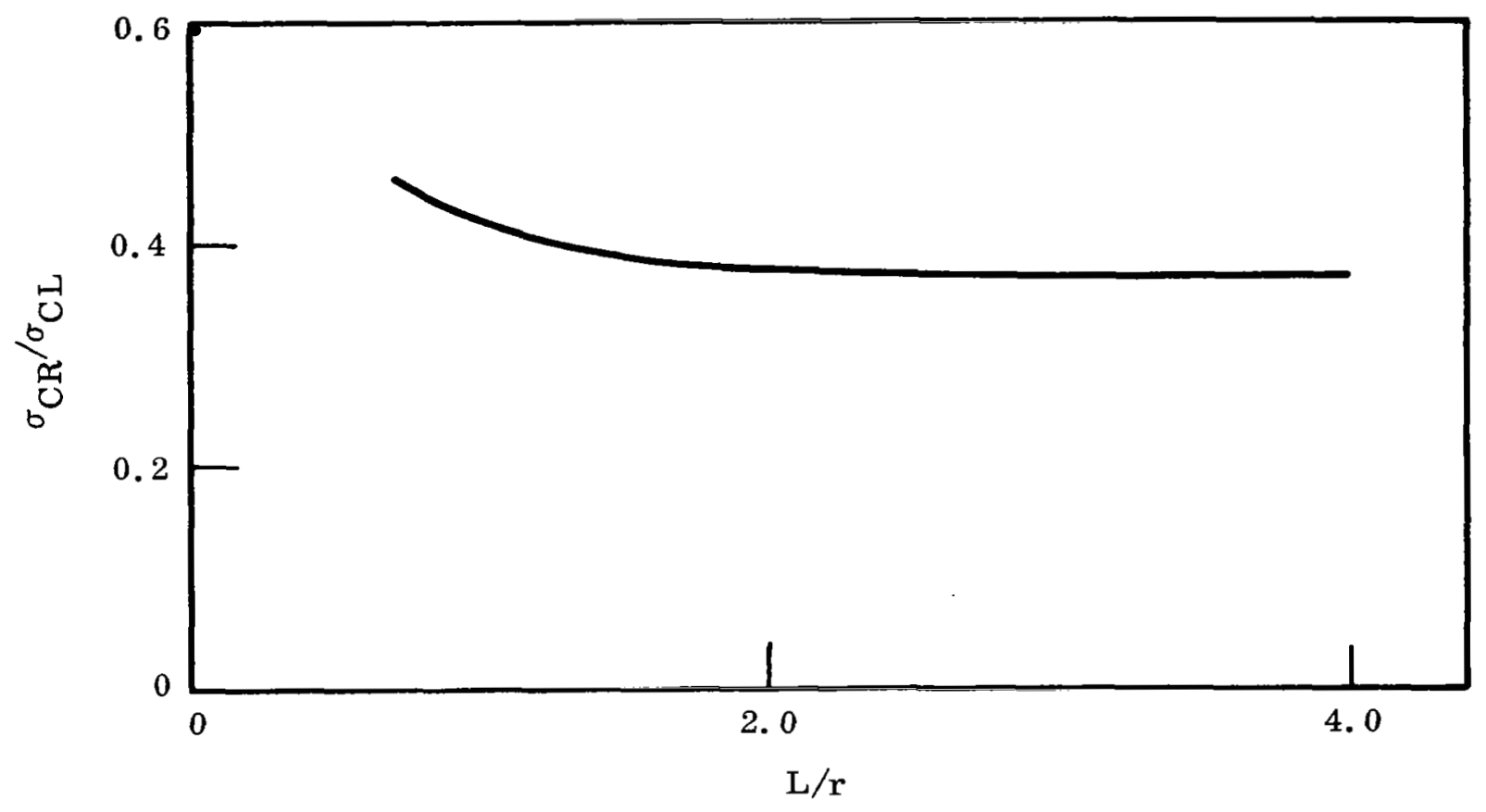

Fig. 1 Buckling of Cylinders With Free Edges 


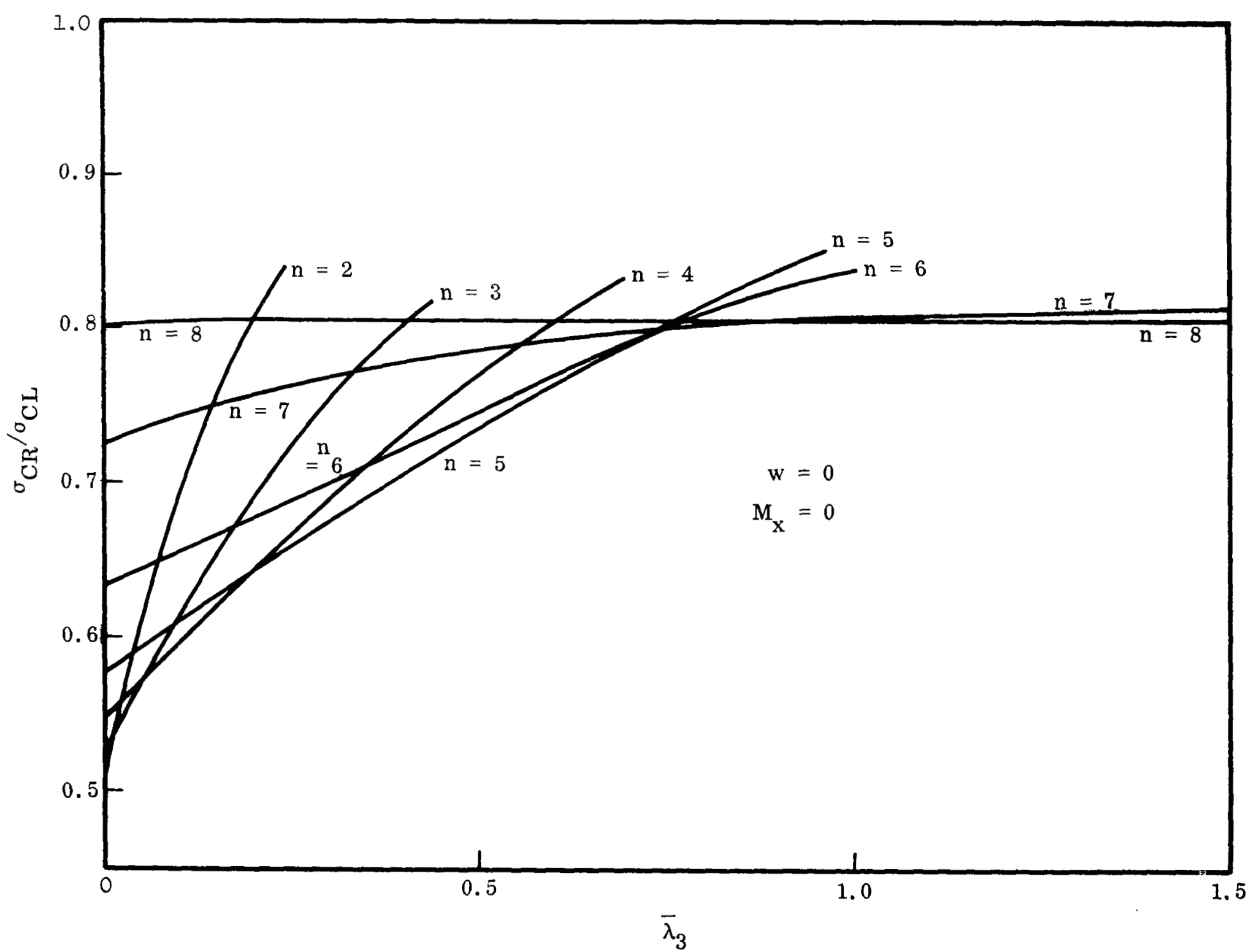

Fig. 2a Critical Loads of Cylinders With Elastic Tangential Restraint: $r / t=100, \quad L / r=0.7$ 


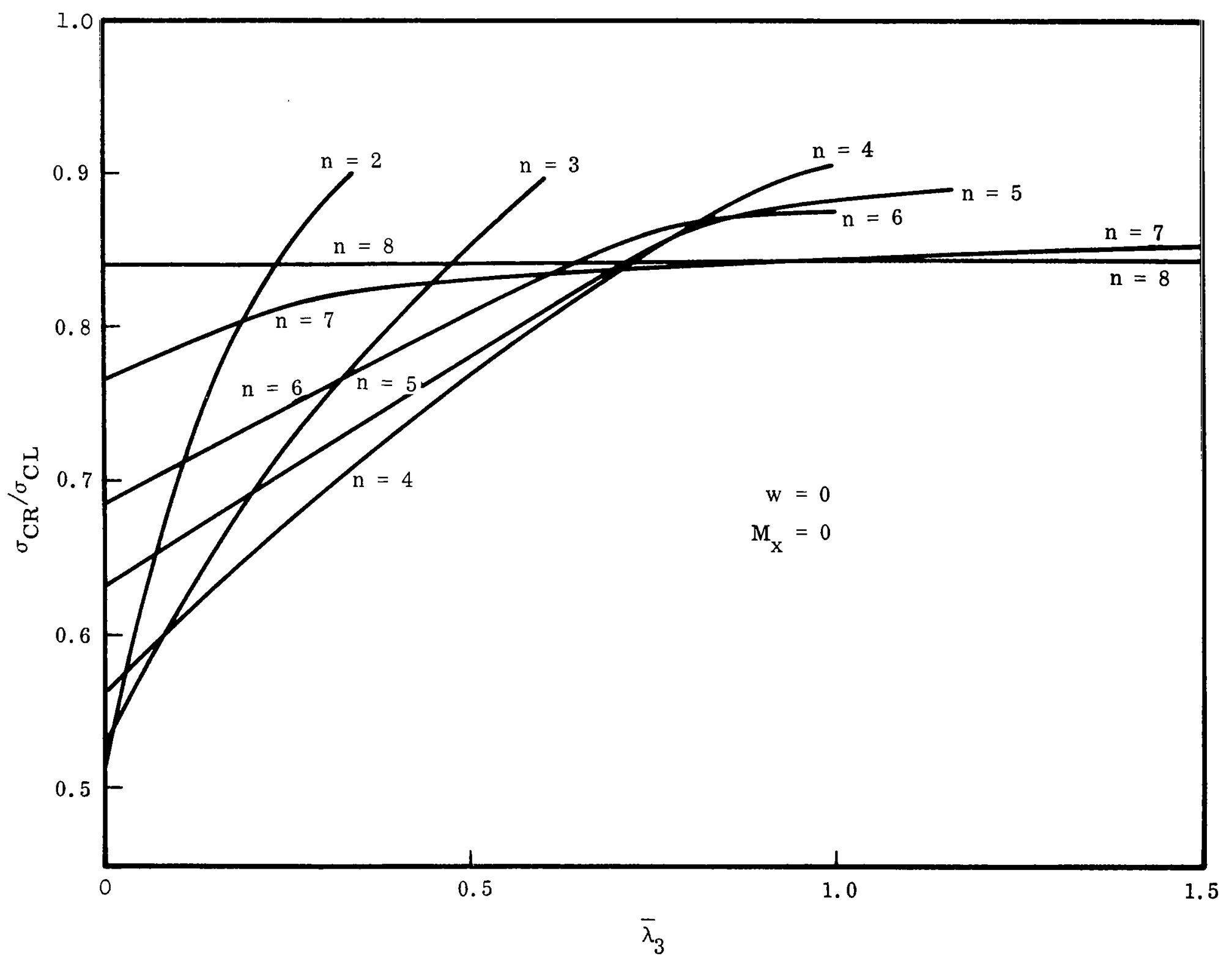




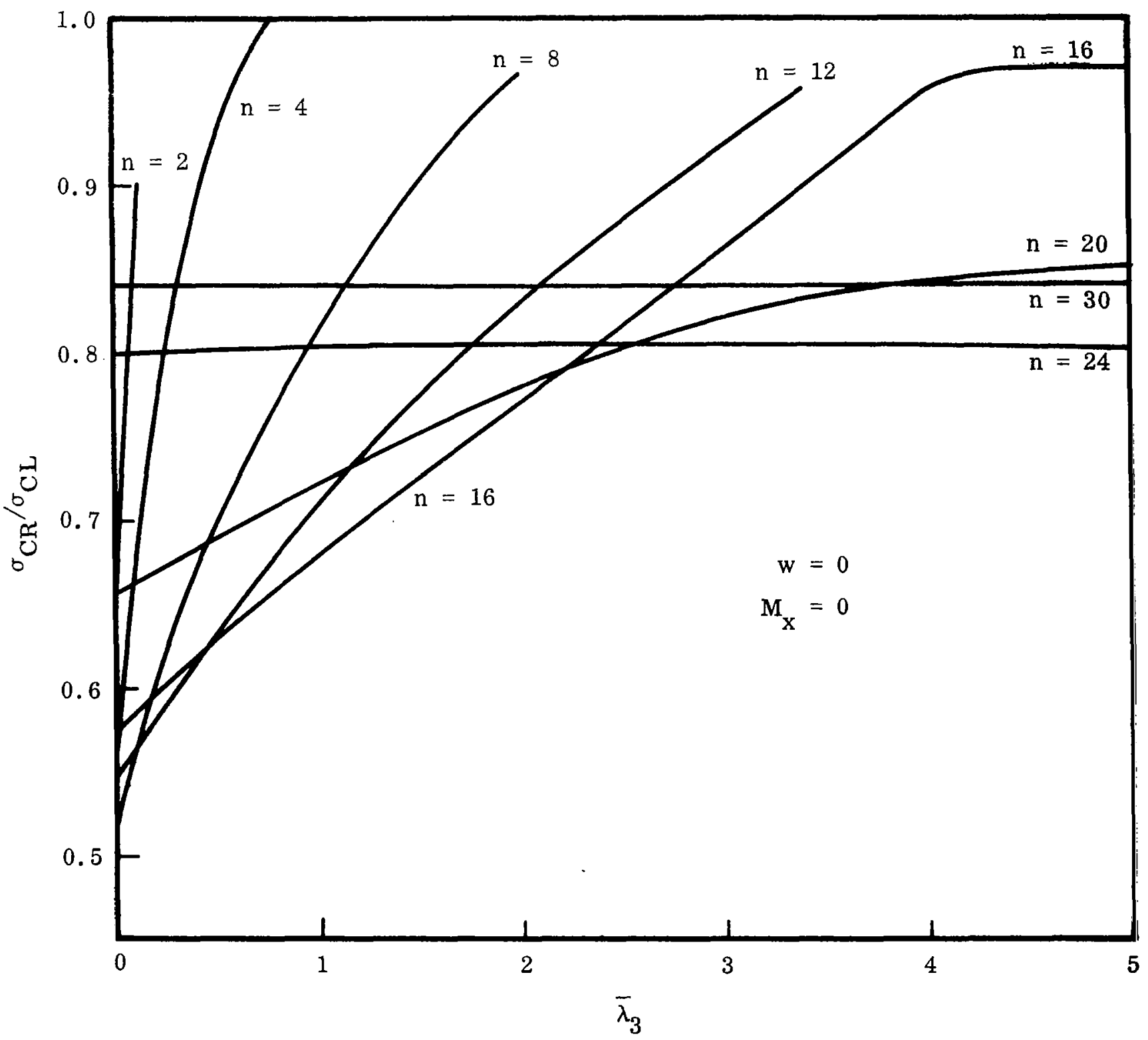

Fig. 2c Critical Loads of Cylinders With Elastic Tangentia! Restraint: $r / t=1000$, $\mathrm{L} / \mathrm{r}=0.222$ 


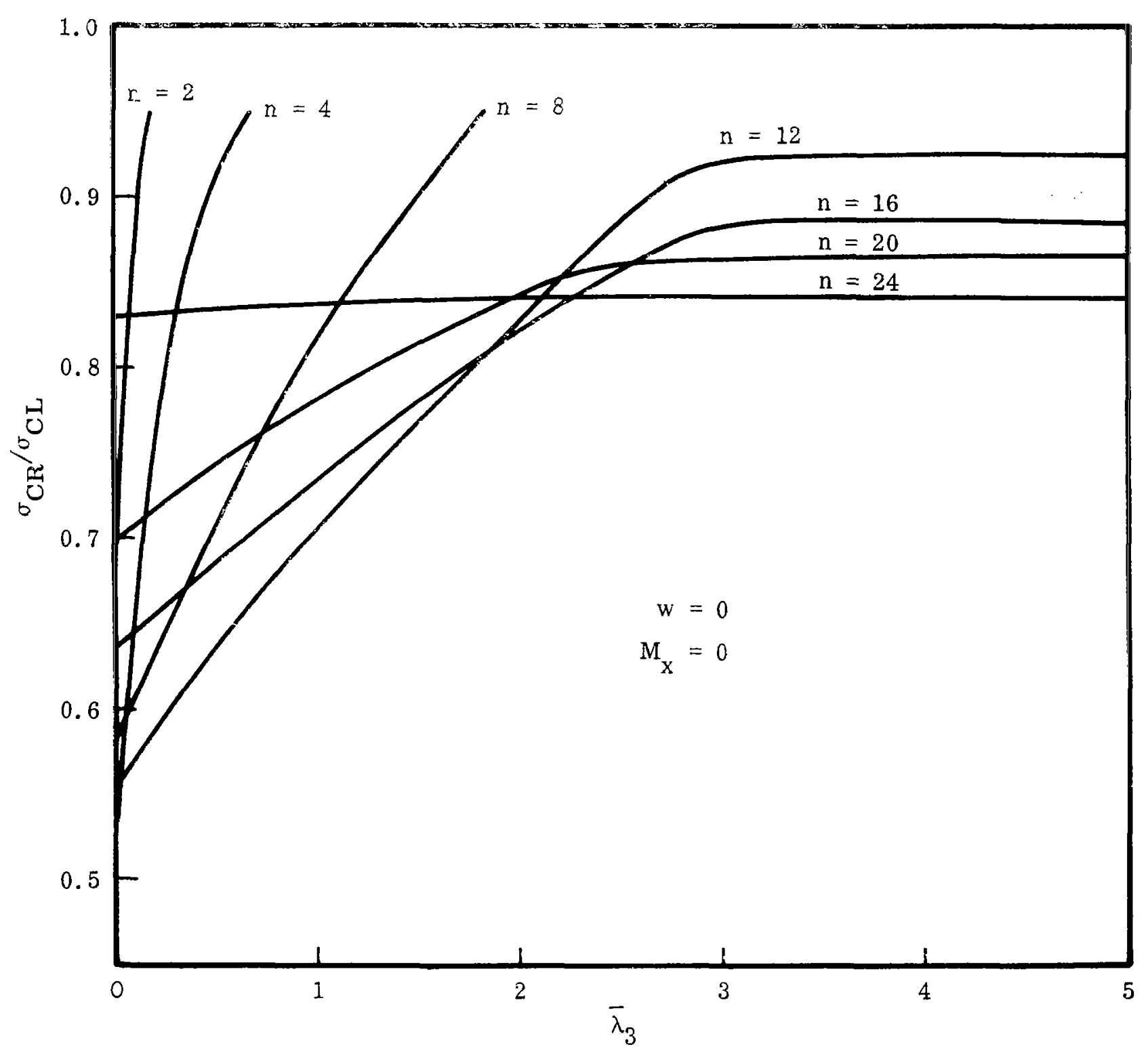

Fig. 2d Critical Loads of Cylinders With Elastic Tangential Restraint: $r / t=1000$, $\mathrm{L} / \mathrm{r}=0.76$ 


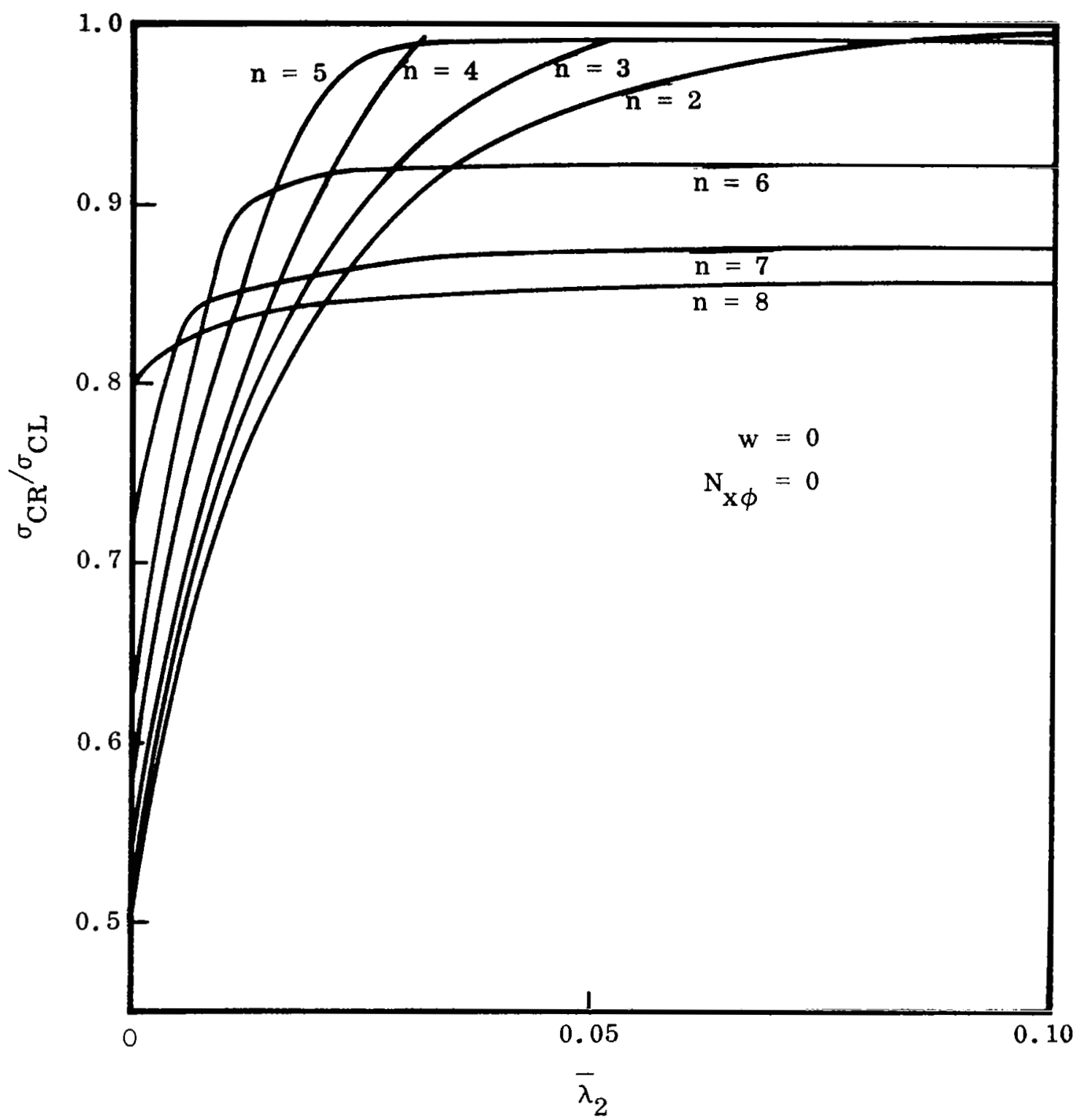

Fig. 3a Critical Loads for Cylinders With Elastic Rotational Edge Restraint: $\mathrm{r} / \mathrm{t}=100, \mathrm{~L} / \mathrm{r}=0.7$ 


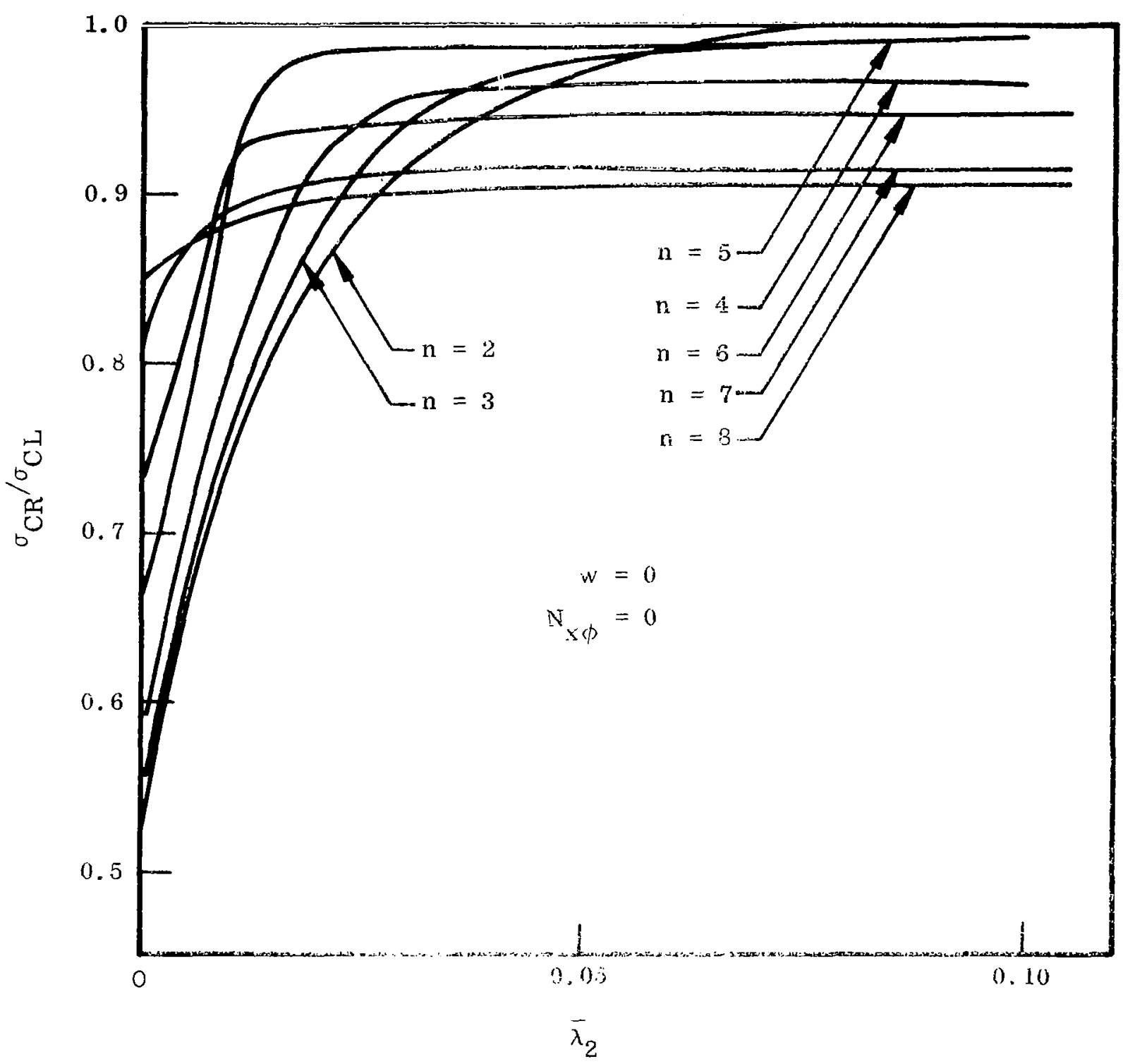

Fig. 3b Critical Loads for Cylinders With Wastic Rotational Edge Restraint: $\mathrm{r} / \mathrm{t}=100, \mathrm{I}: \mathrm{r}=2.4$ 


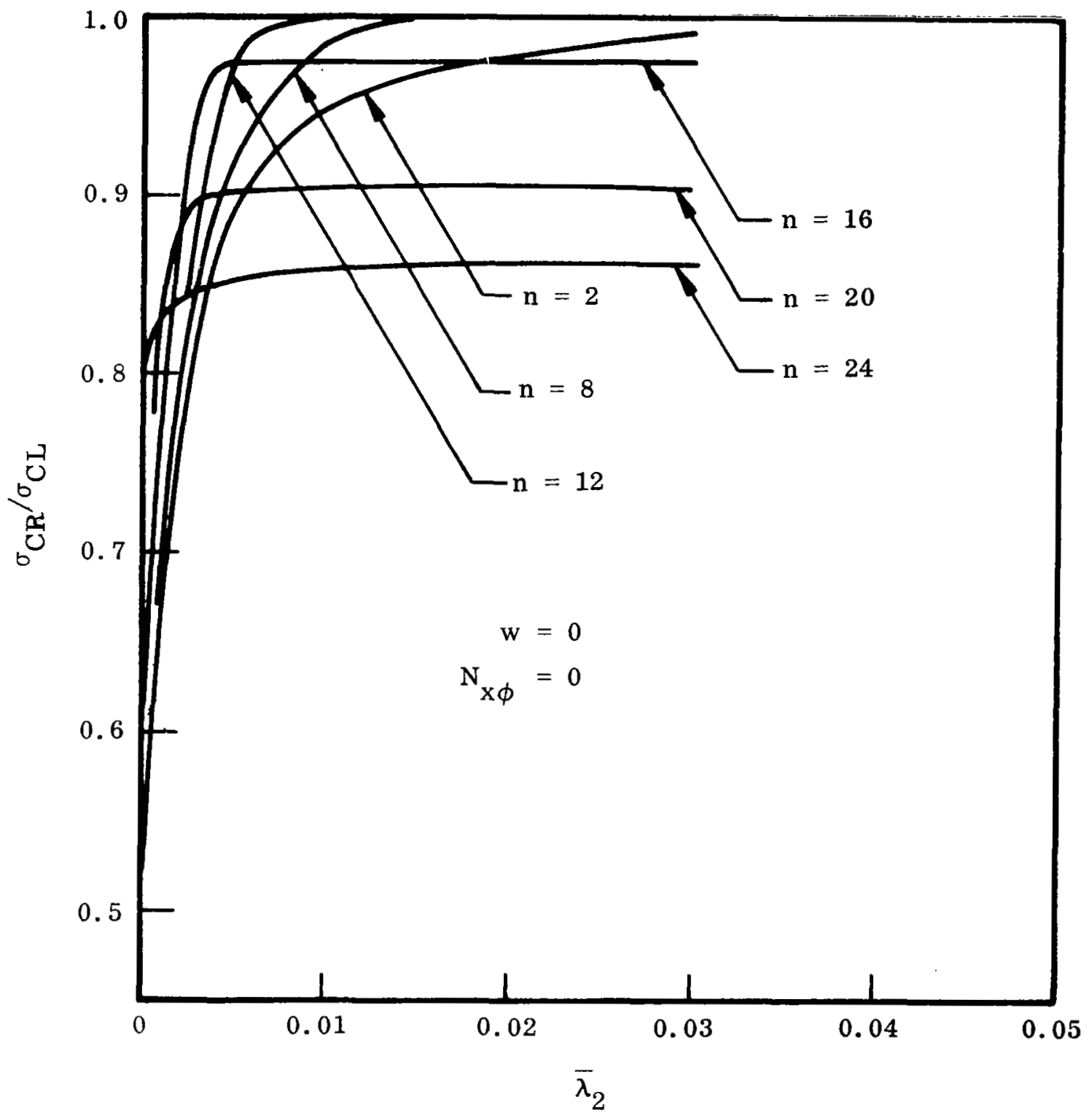

Fig. 3c Critical Loads for Cylinders With Elastic Rotational Edge Restraint: $\mathrm{r} / \mathrm{t}=1000, \mathrm{~L} / \mathrm{r}=0.222$ 


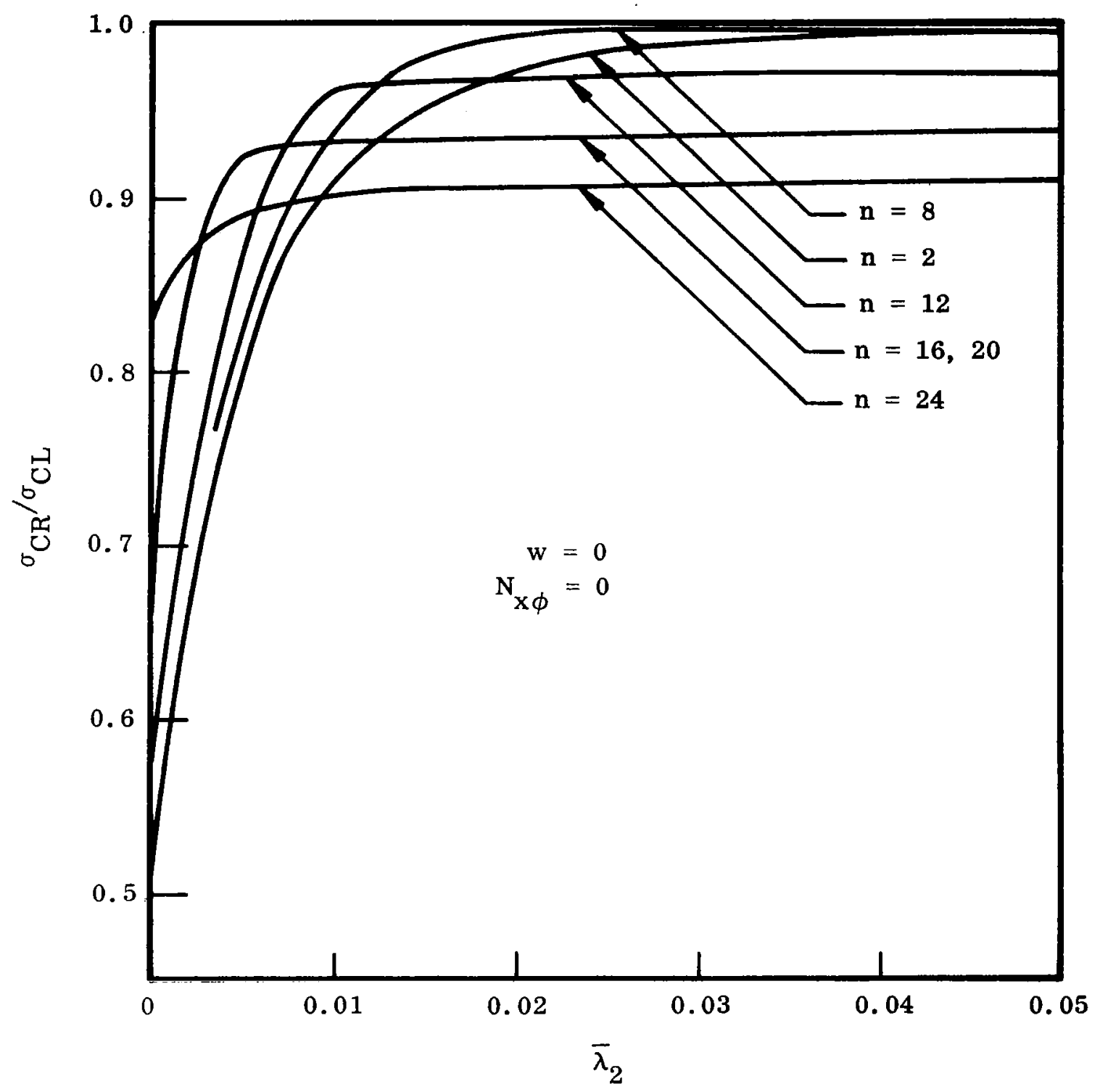

Fig. 3d Critical Loads for Cylinders With Elastic Rotational Edge Restraint: $\mathrm{r} / \mathrm{t}=1000, \mathrm{~L} / \mathrm{r}=0.76$ 


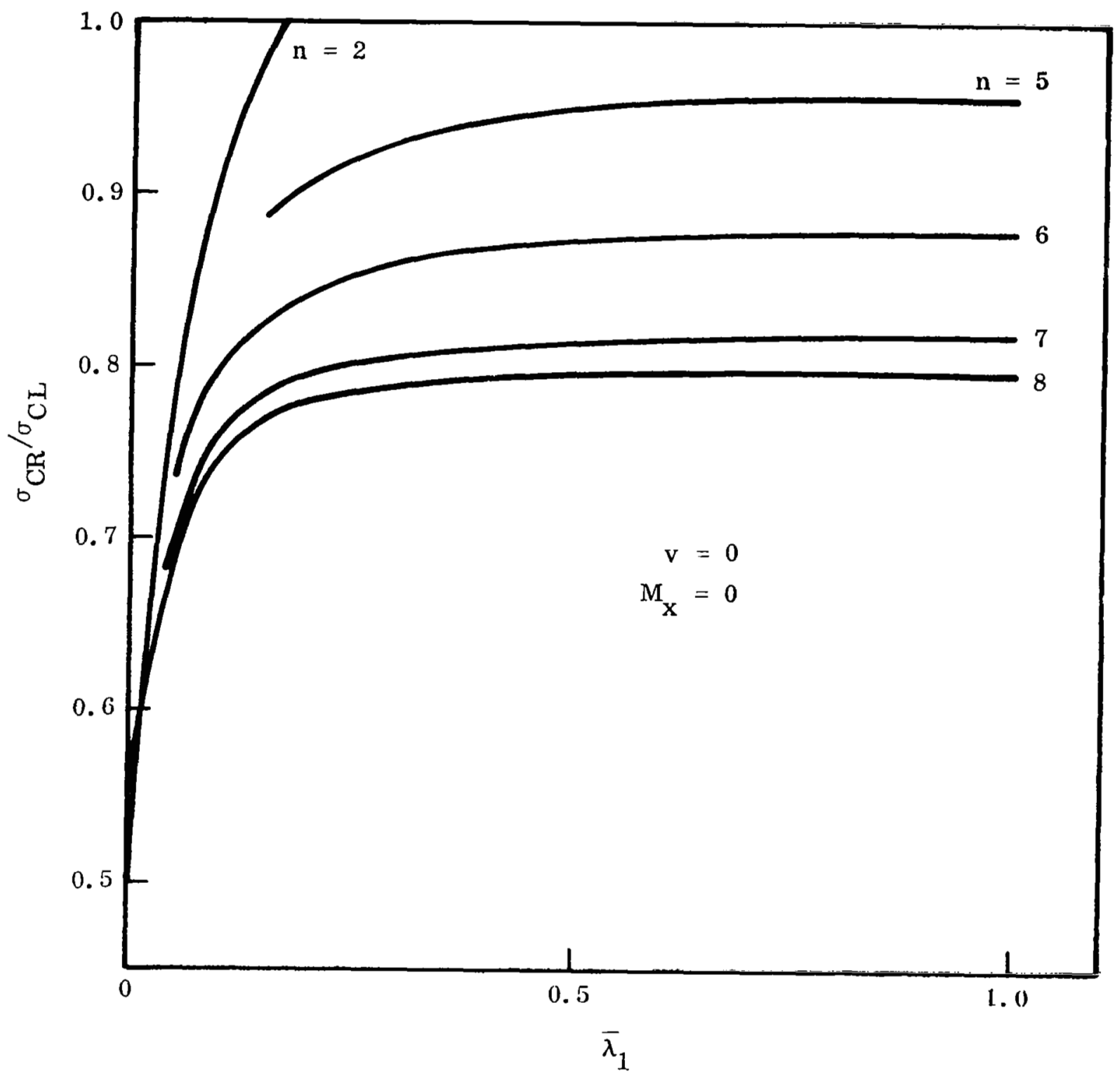

Fig. 4a Critical Loads for Cylinders With Elastic Radial Edge Restraint: $\mathrm{r} / \mathrm{t}=100, \mathrm{~L} / \mathrm{r}=0.7$ 


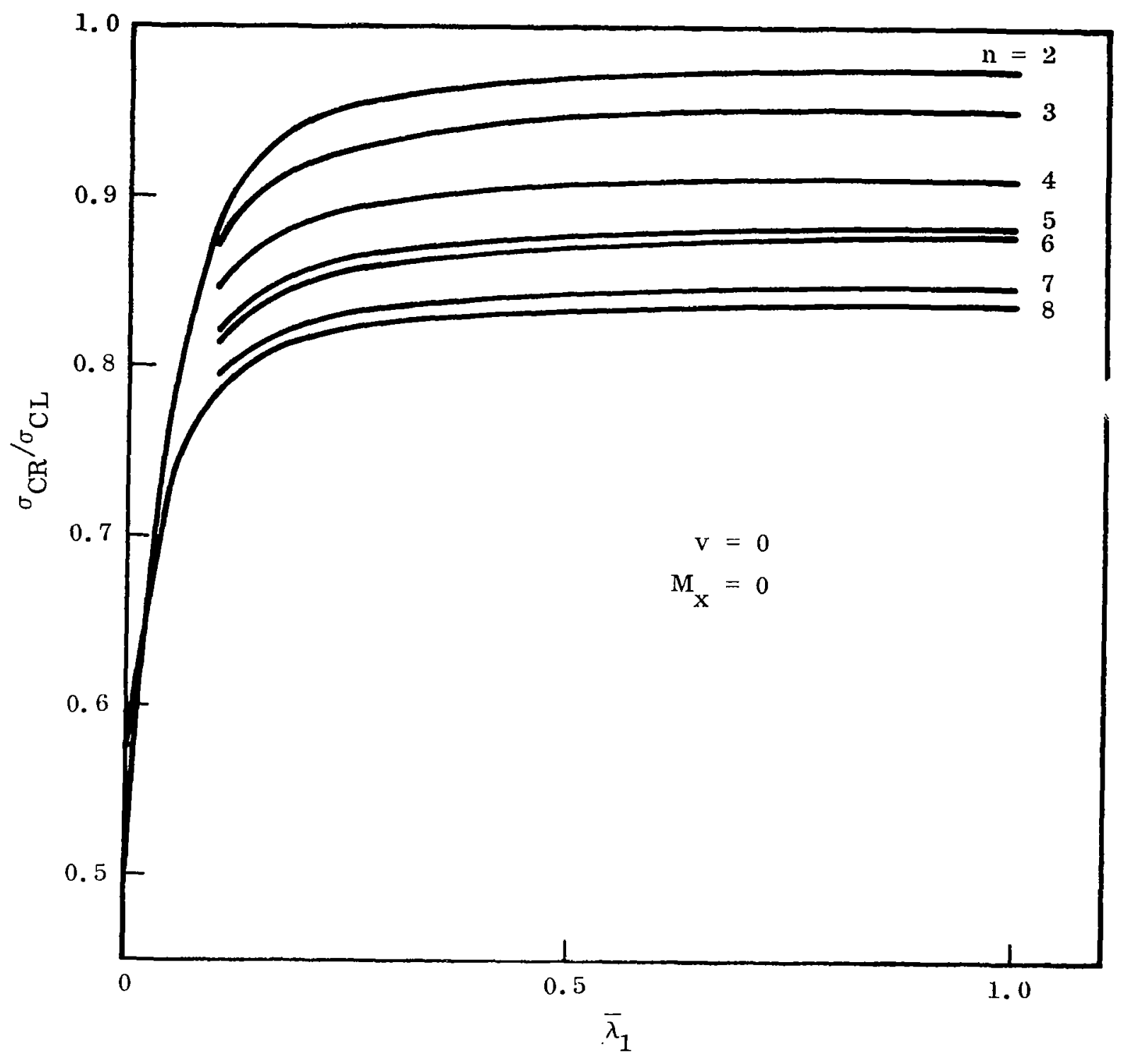

Fig. 4b Critical Loads for Cylinders With Elastic Radial Edge Restraint: $\mathrm{r} / \mathrm{t}=100, \mathrm{~L} / \mathrm{r}=2.4$ 


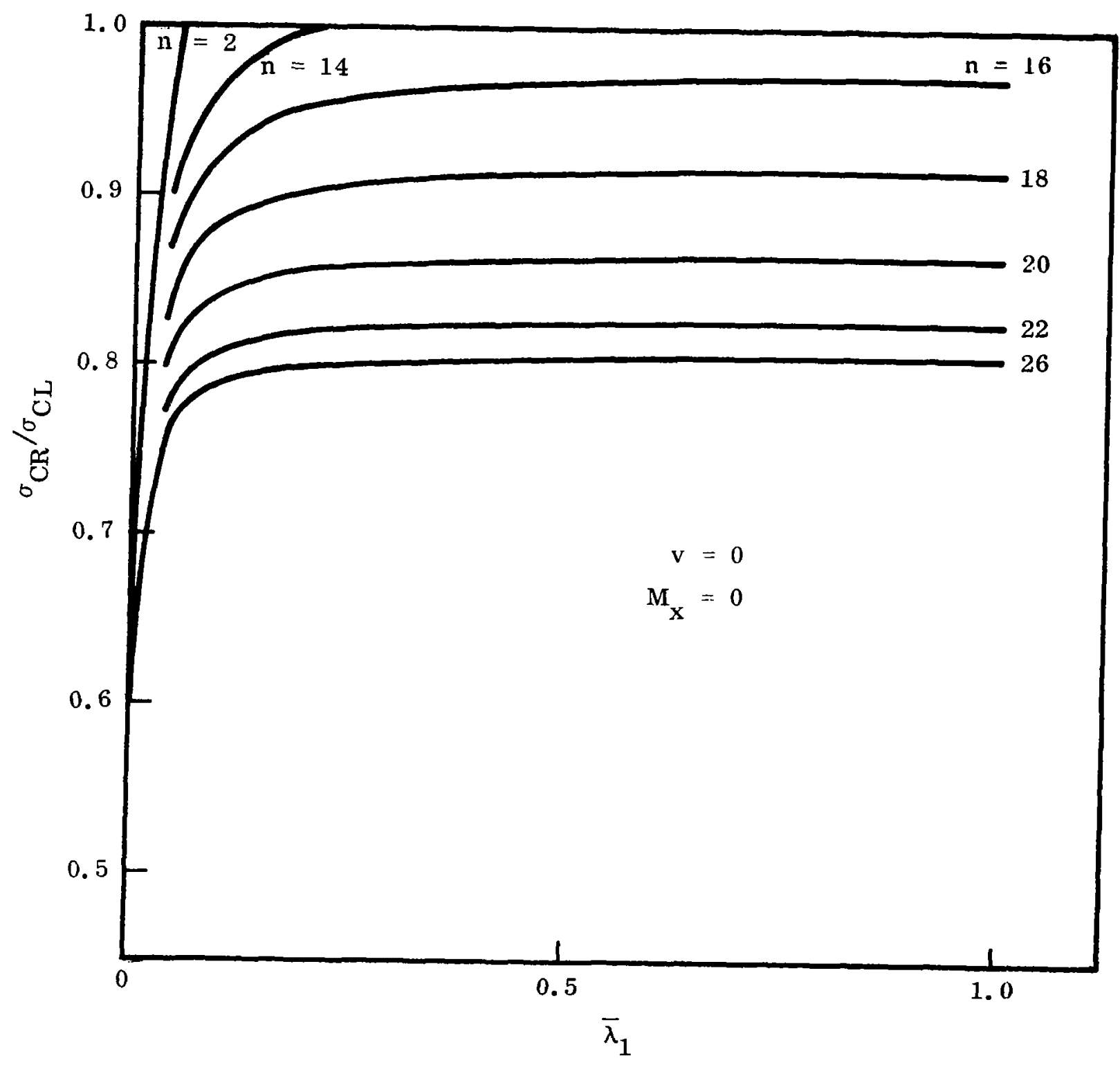

Fig. 4c Critical Loads for Cylinders With Elastic Radial Edge Restraint: $\mathrm{r} / \mathrm{t}=1000, \mathrm{~L} / \mathrm{r}=0.222$ 


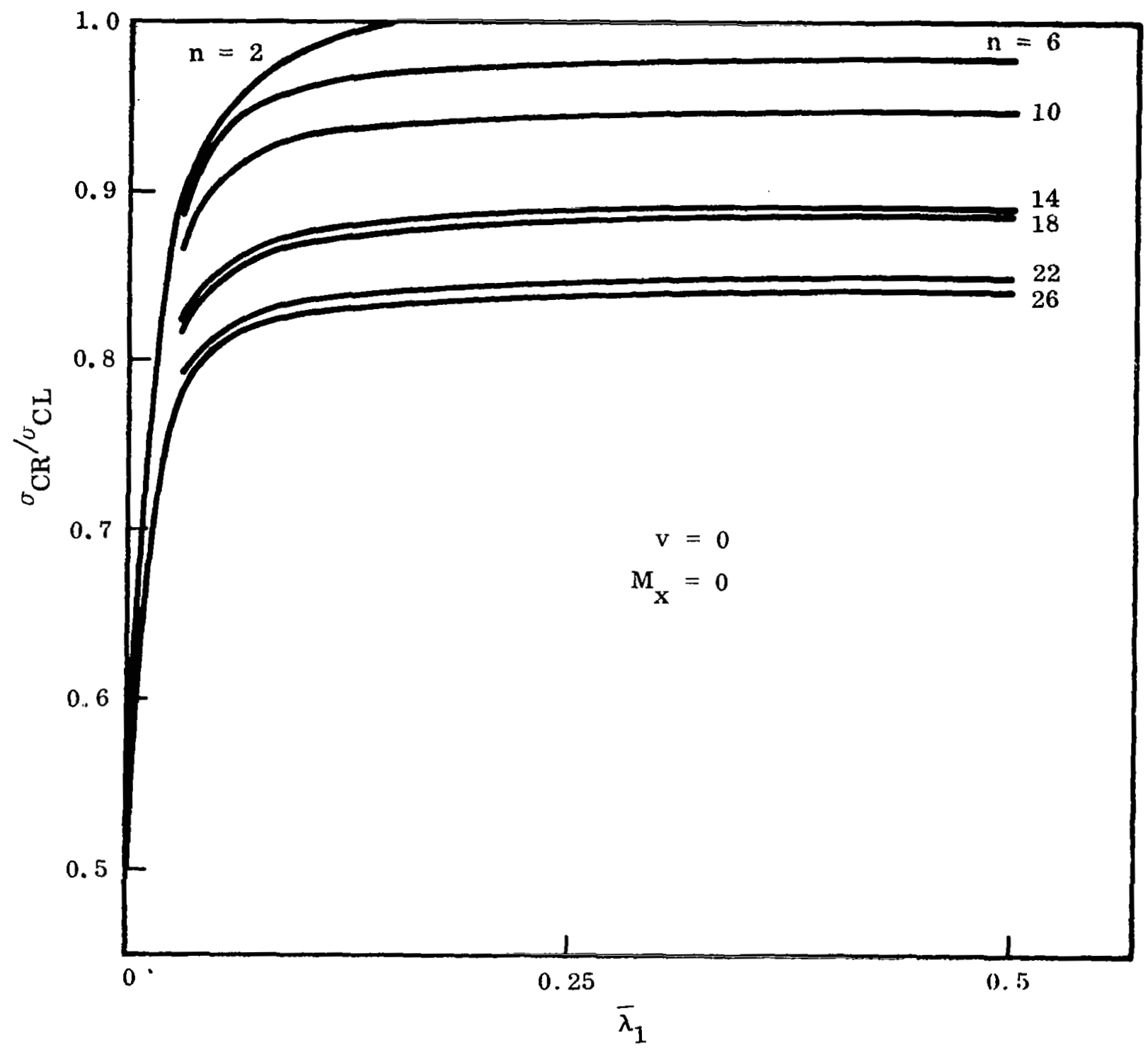

Fig. 4d Critical Loads for Cylinders With Elastic Radial Edge Restraint: $r / t=1000, L / r=0.76$ 


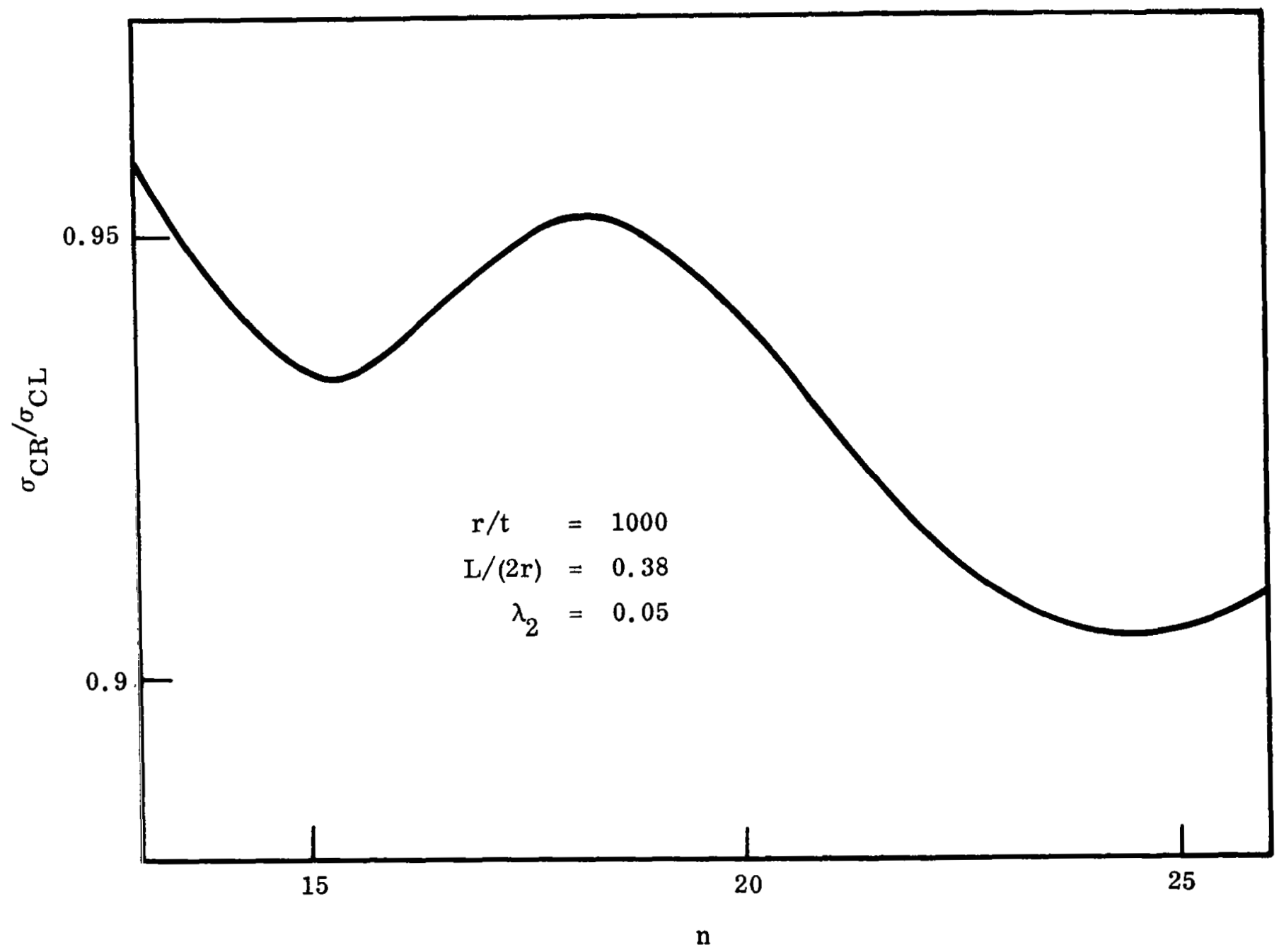

Fig. 5 Variation of Critical Load With Wave Number 


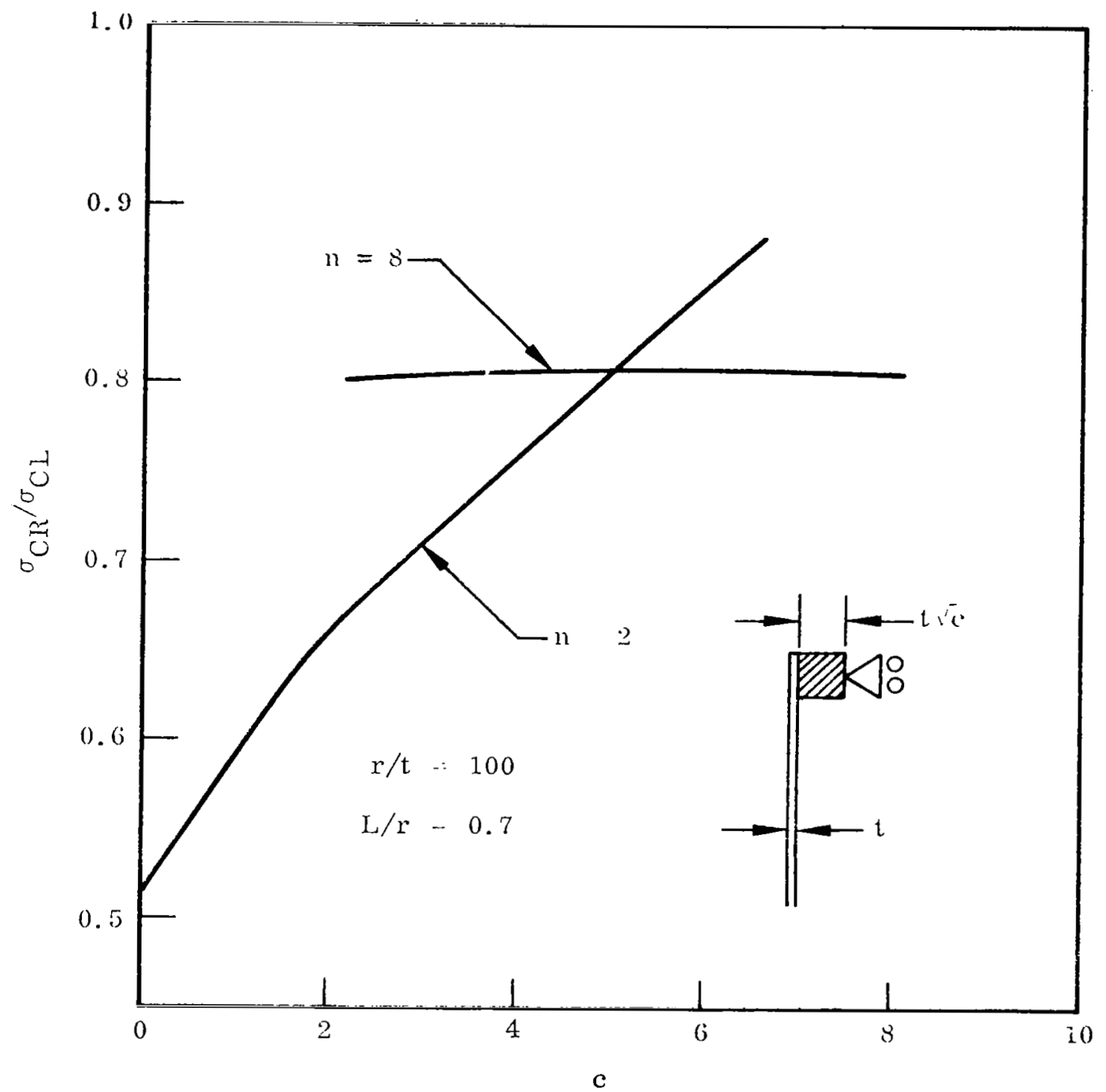

Fig. 6 C'itical labd of Cylindel With Supported End ling. (Torsional stifllless of ring in cimitted.) 


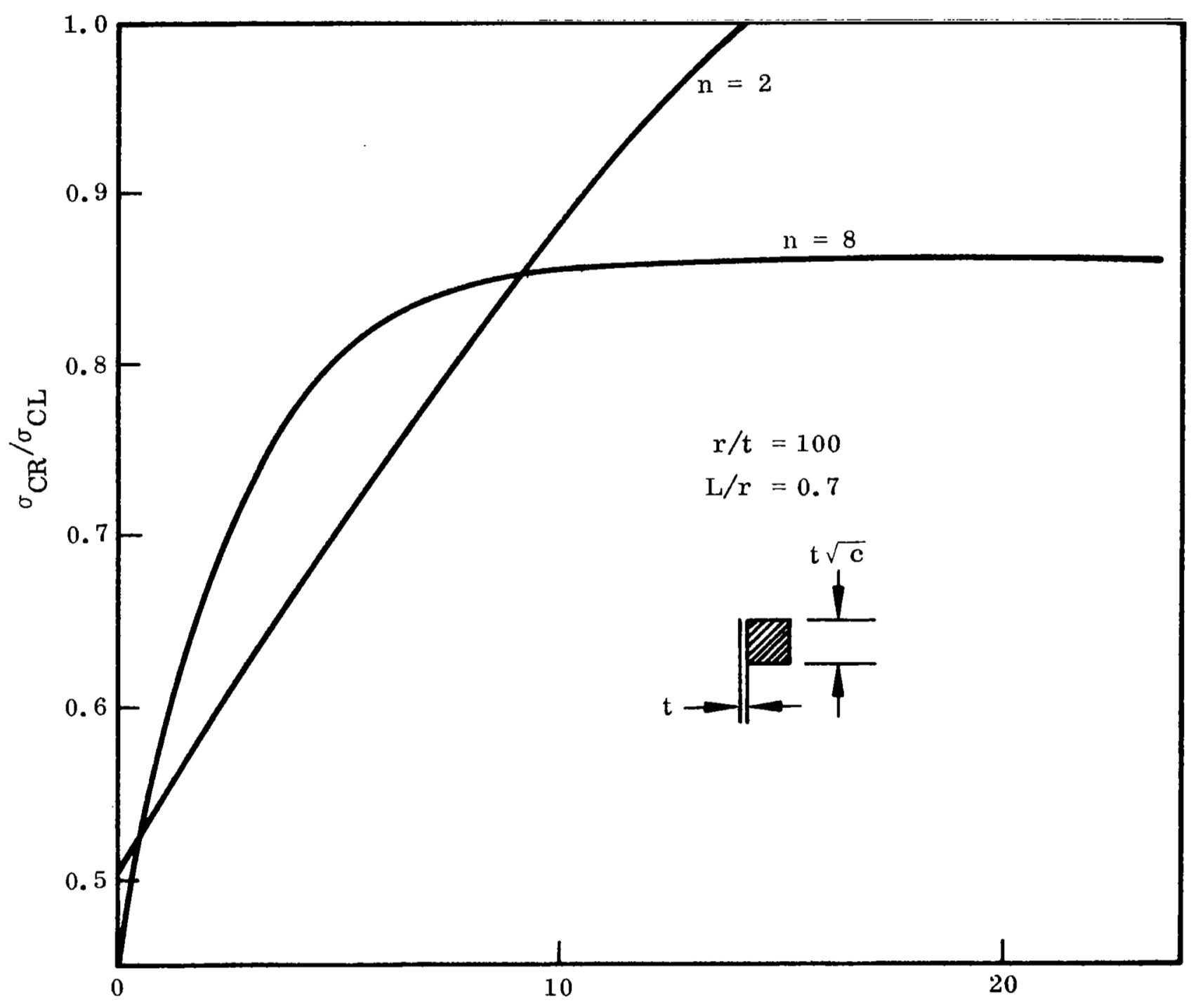

Fig. 7 Critical Load of Cylinder With End Ring 


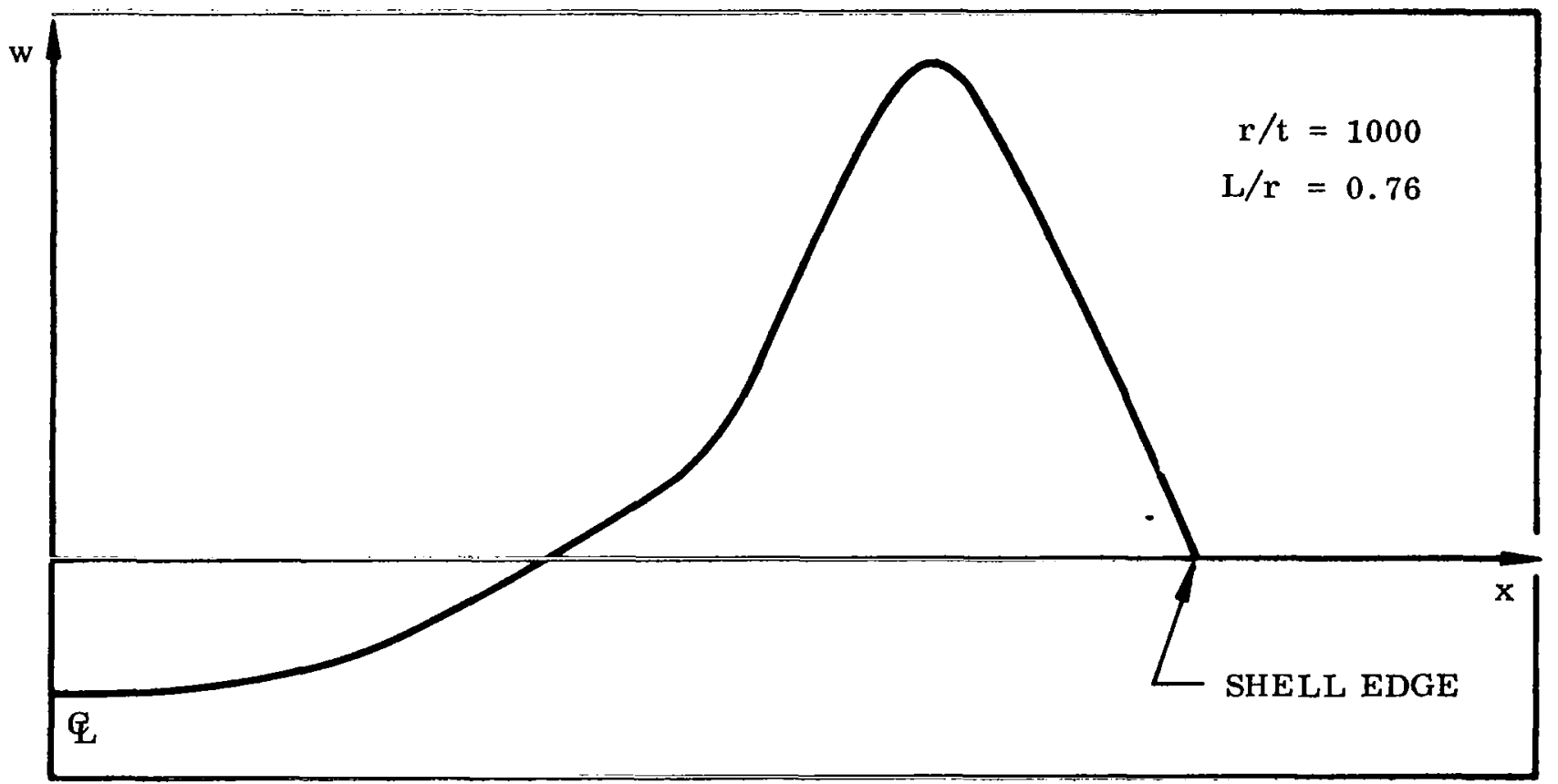

Fig. 8 Buckling Mode for Simply Supported Cylinder 


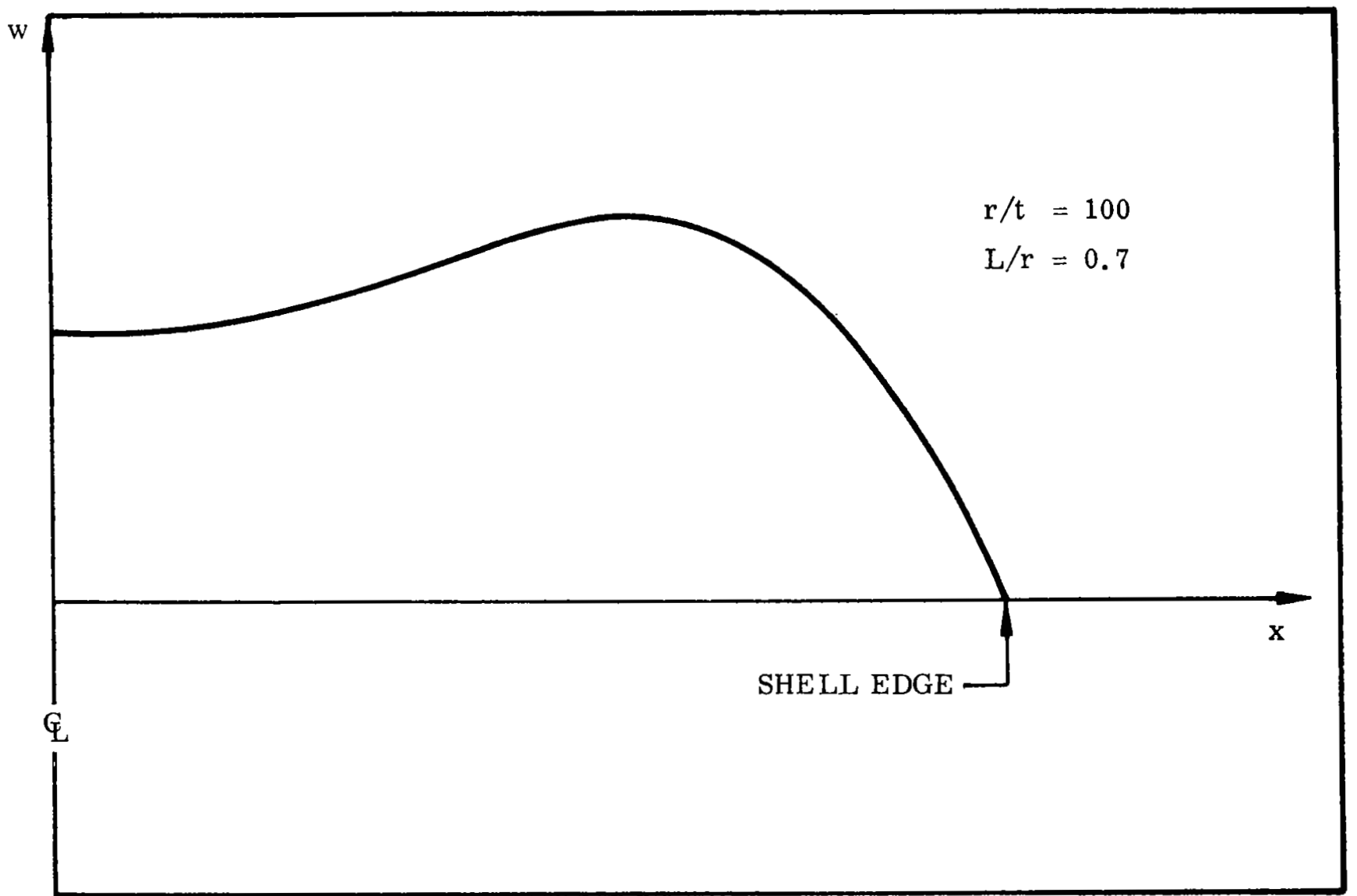

Fig. 9 Buckling Mode for Cylinder With the Edges Free in the Tangential Direction 


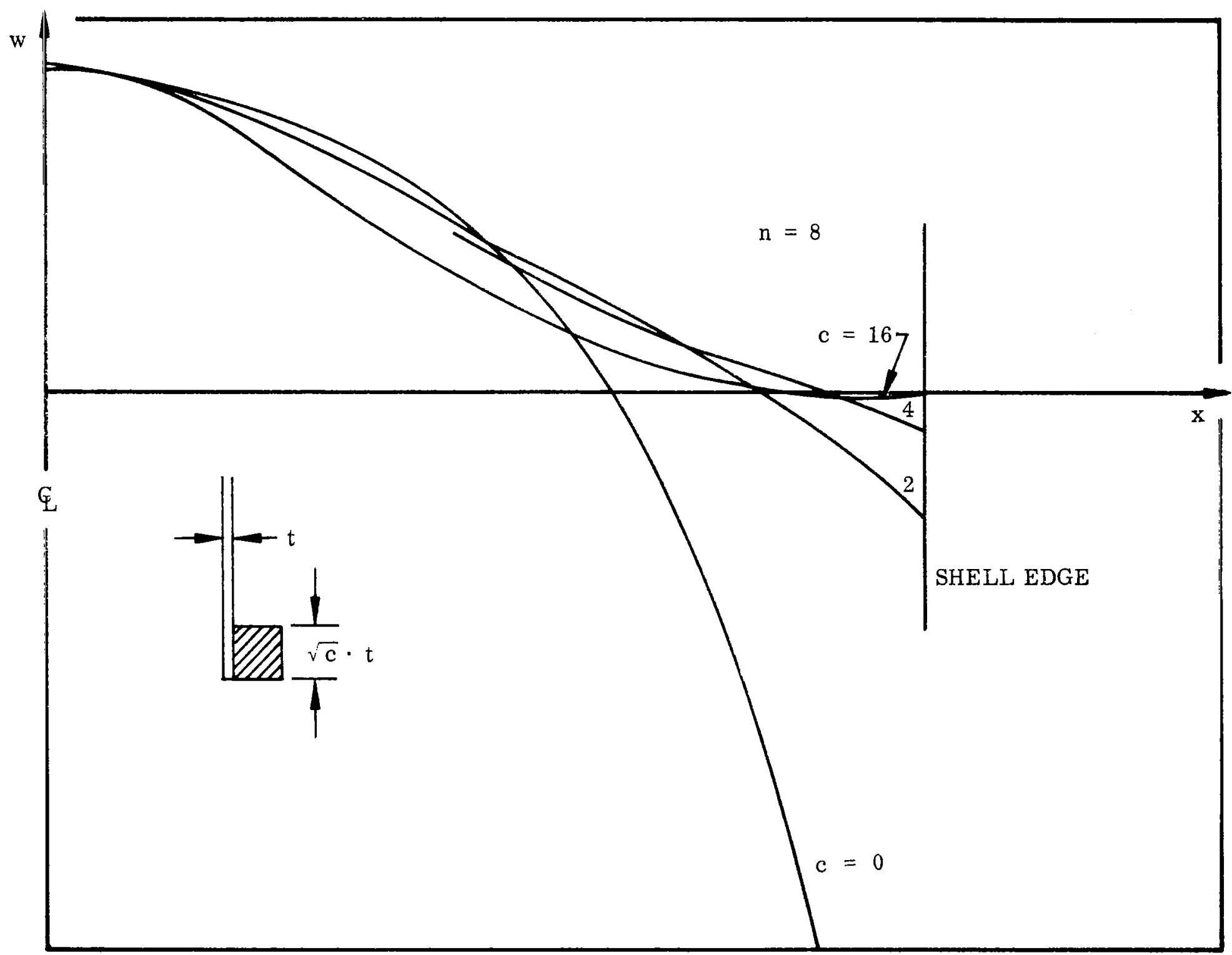




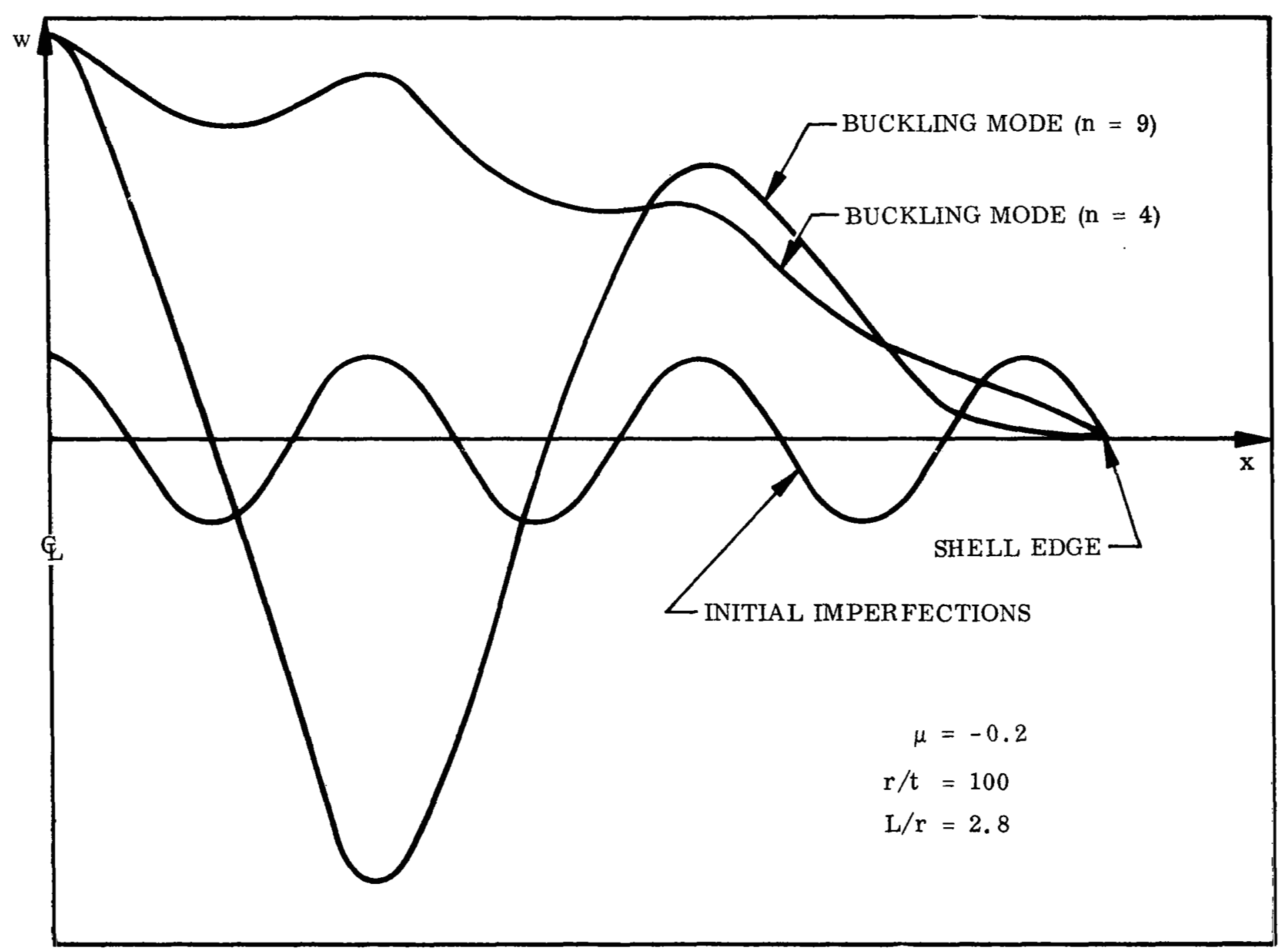

Fig. 11 Buckling Modes for Imperfect Cylinders 


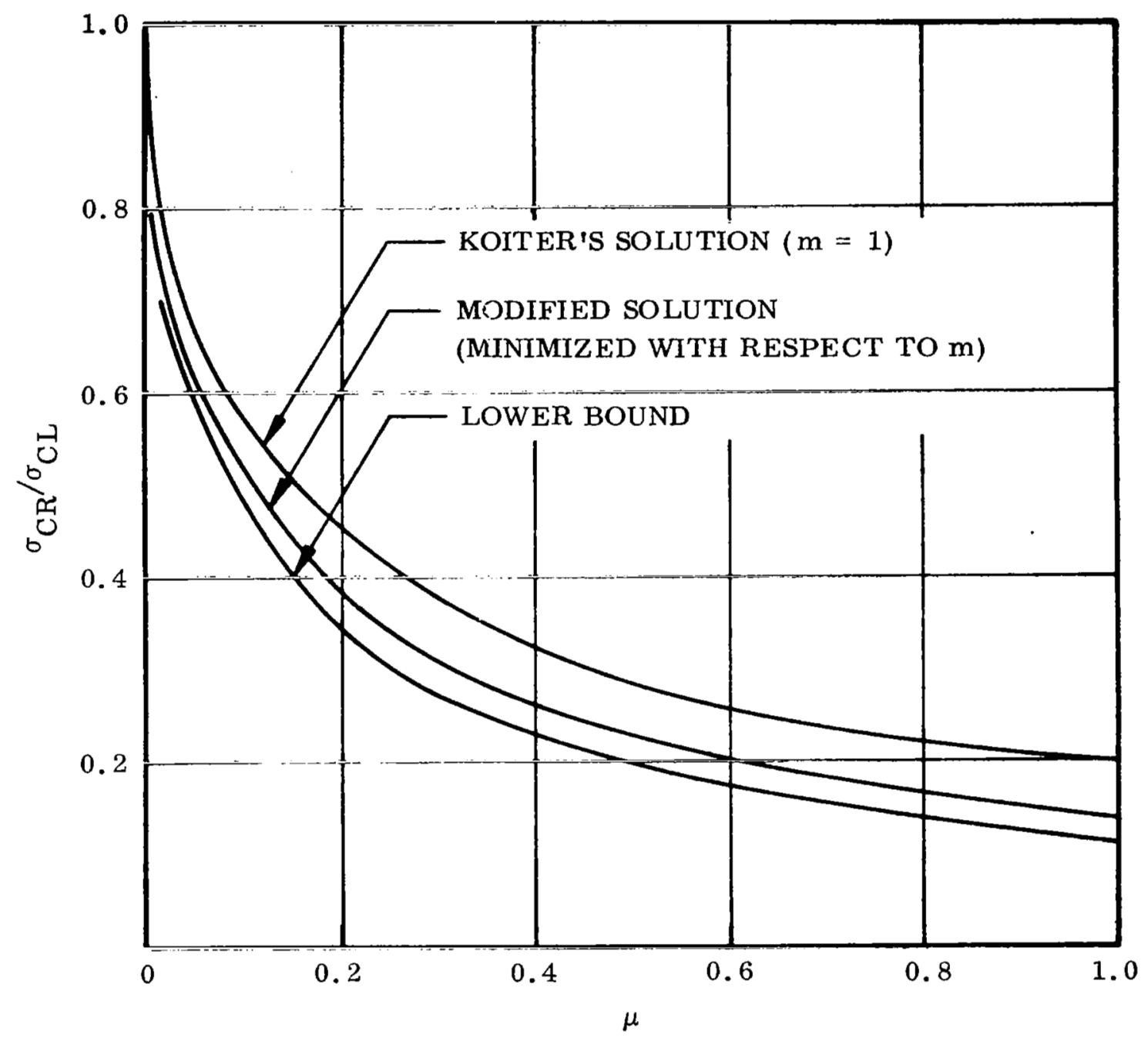

Fig. 12 Buckling of Long Cylinders With Periodic Initial Imperfections of Amplitude $\mu \mathrm{t}$ 
品

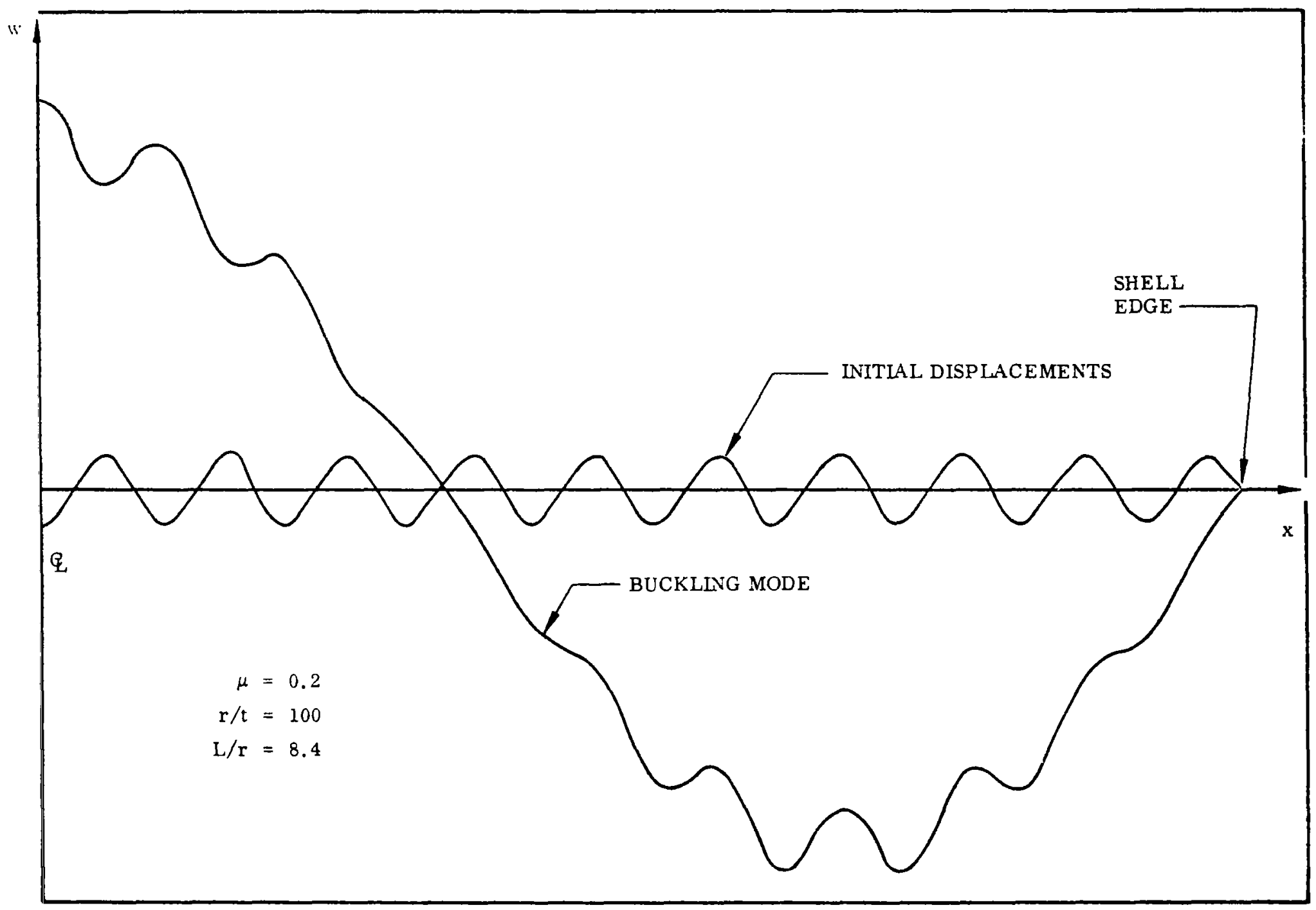

Fig. 13 Buckling Mode for Long Cylinder 

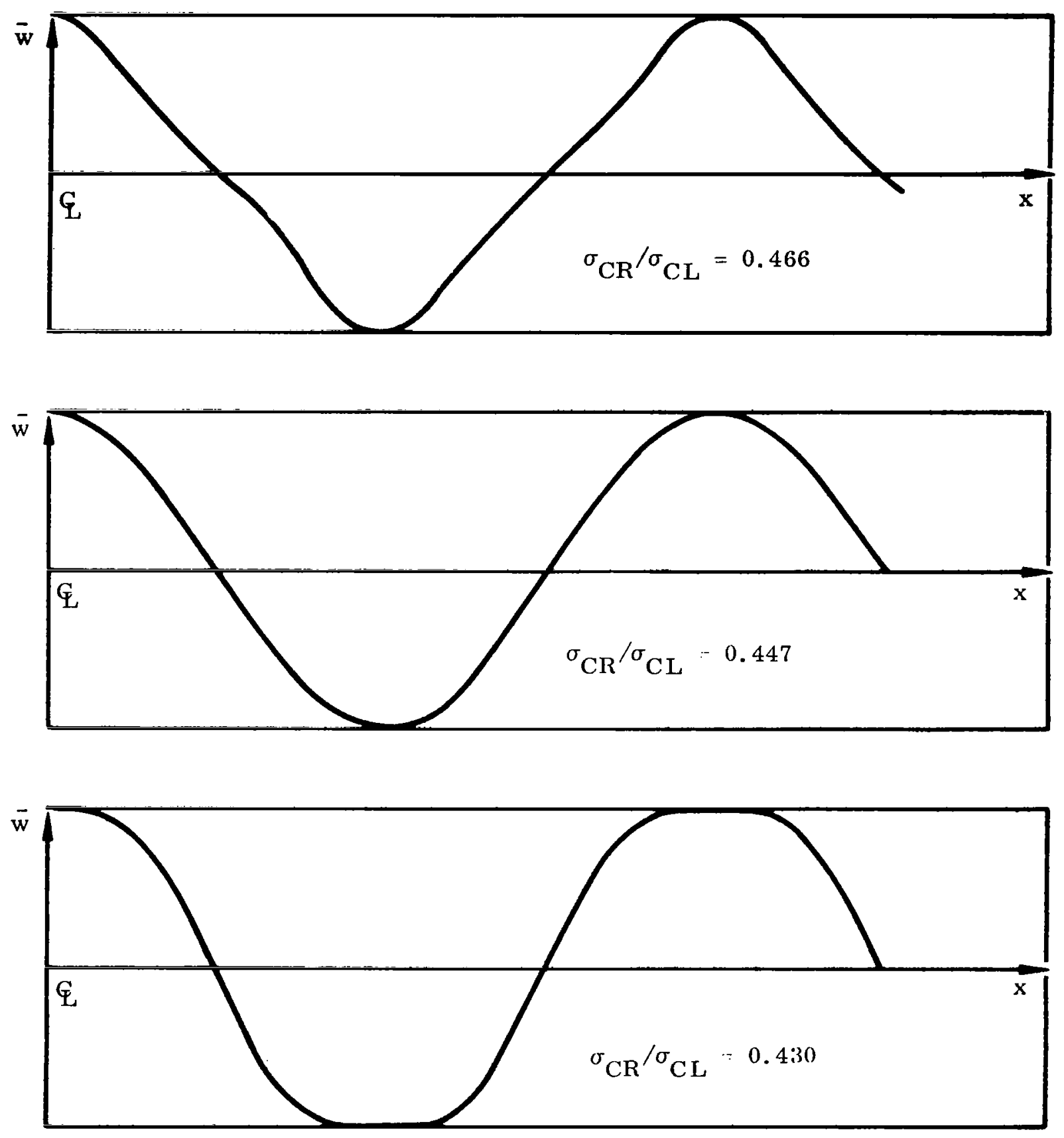

Fig. 14 Influence of Shape of Initial Imperfection on Critical Load 


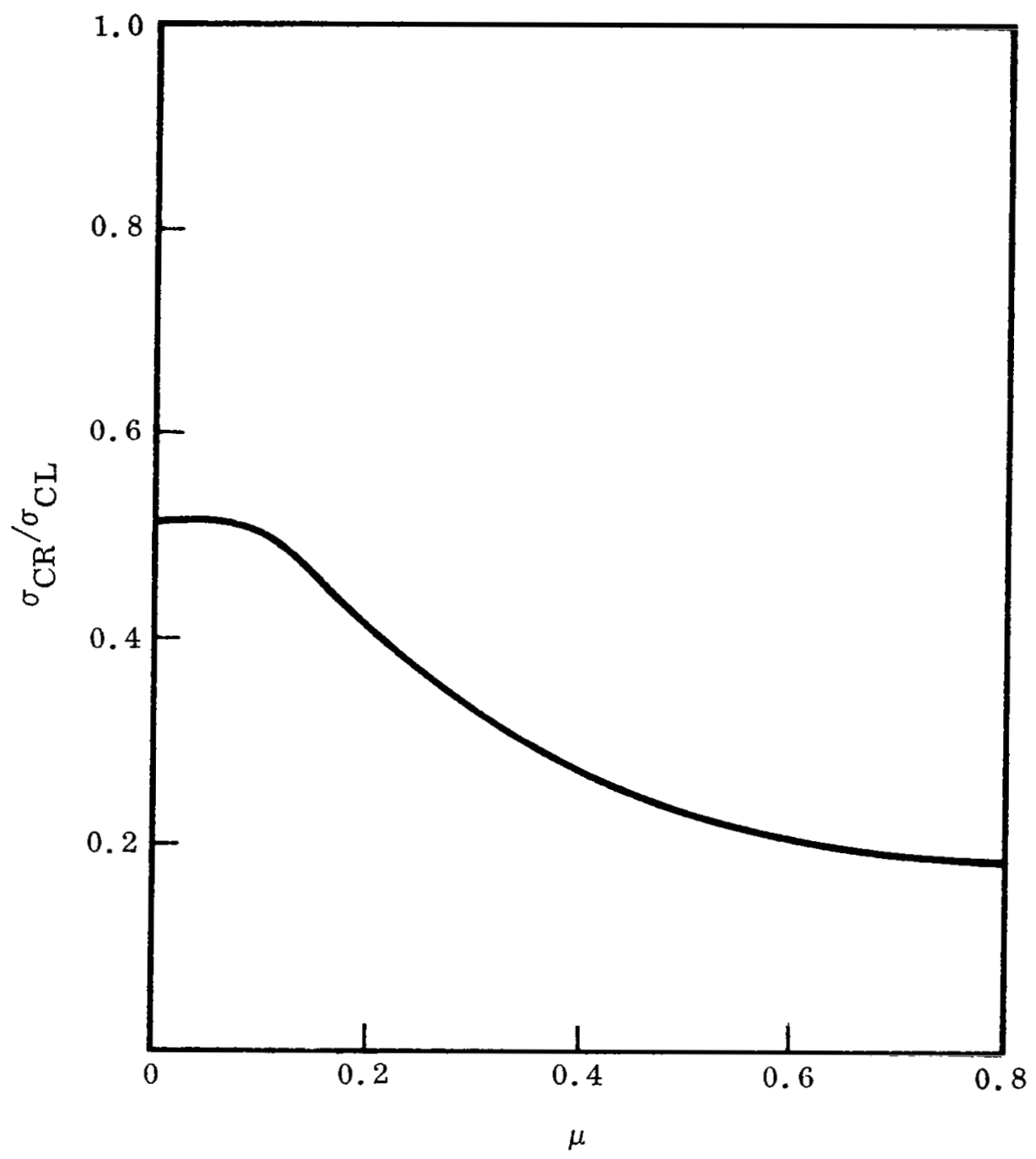

Fig. 15 Influence of Initial Imperfections on Cylinder With $\mathrm{N}_{\mathrm{XY}}=0$ at Edge 


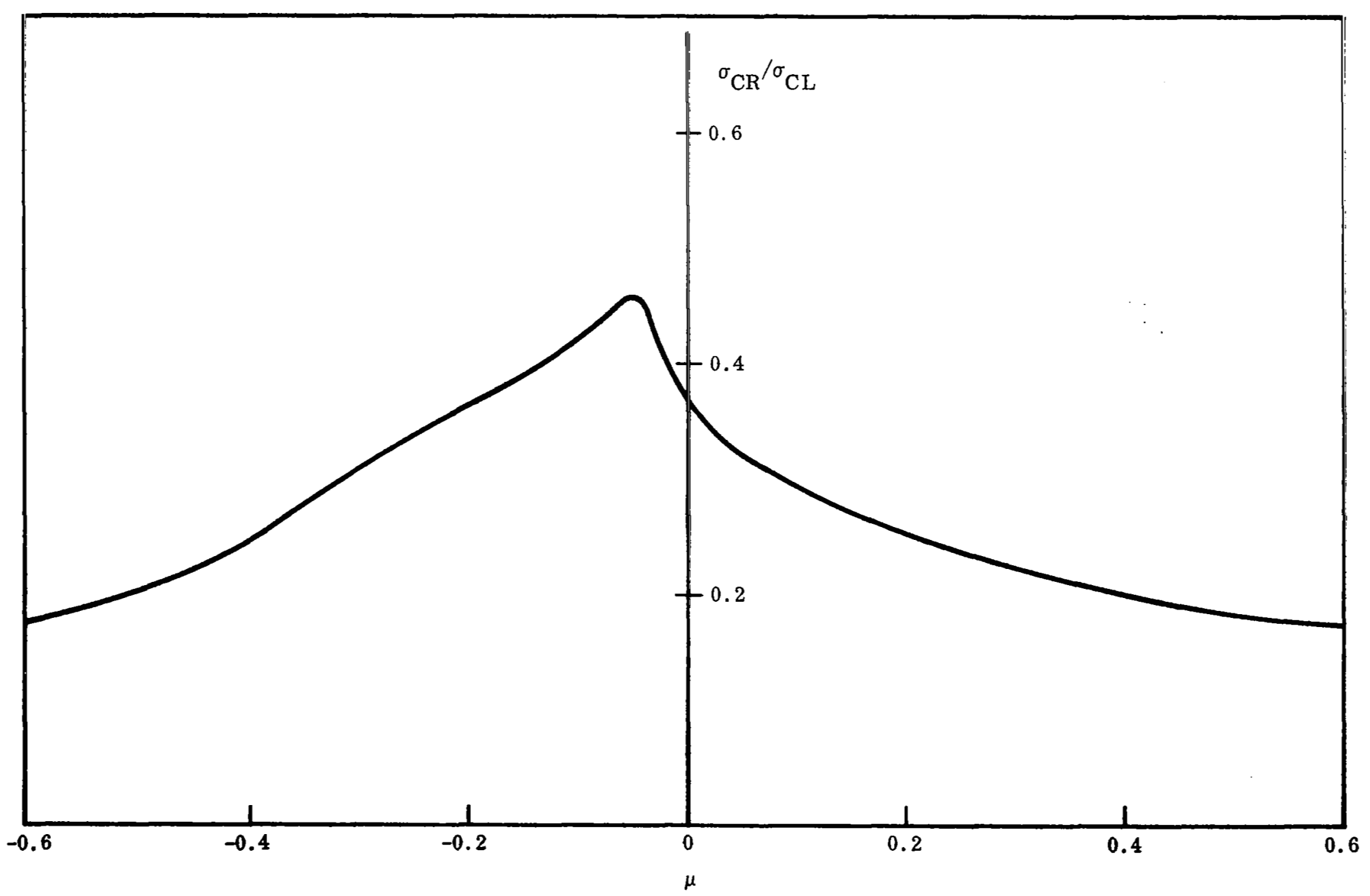

Fig. 16 Influence of Initial Imperfections on Cylinder W'ith Free Edge 


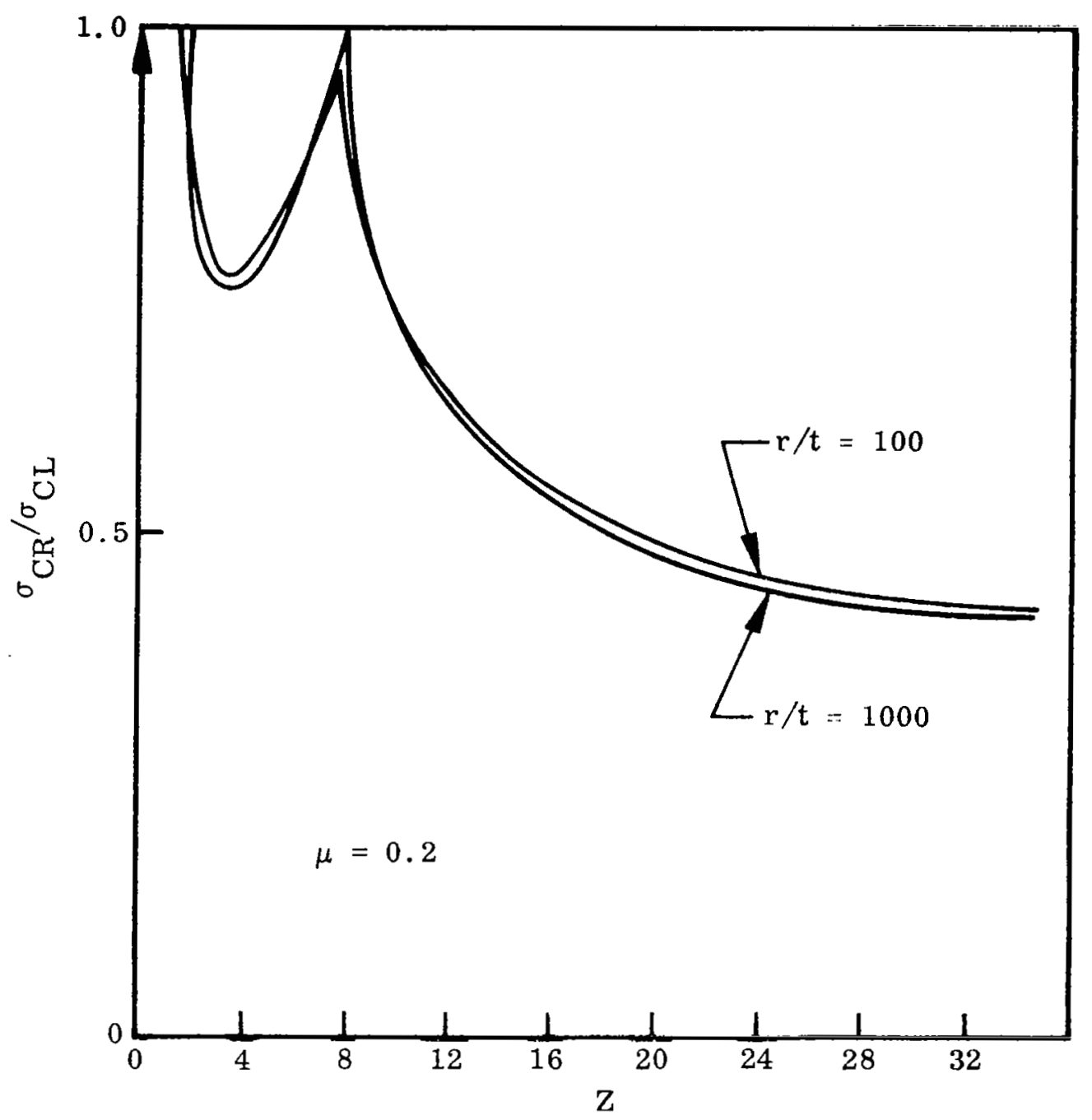

l'ig. 17 Influence of Initial Imperfections on Buckling Load of Short Cylinders 

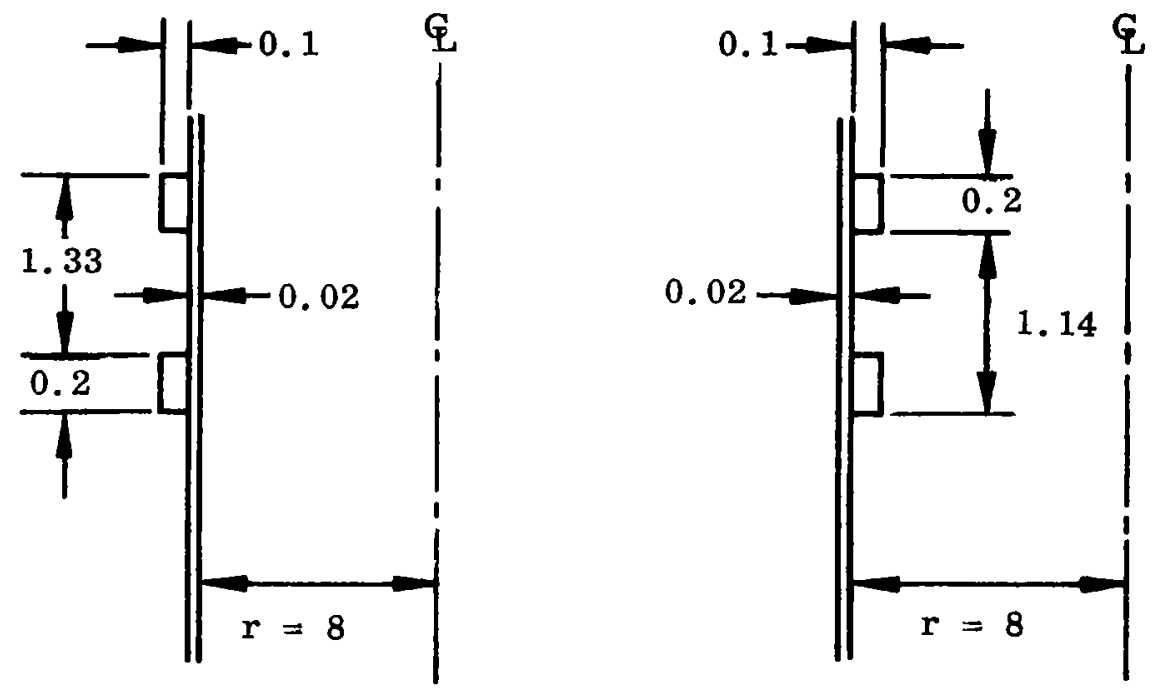

CYLINDER LENGTH 16 IN.

Fig. 18 Geometry of Tested Cylinders 
Table I

TEST OF RING-STIFFENED CY LINDERS

\begin{tabular}{|l|l|l|r|r|r|r|}
\hline \multirow{2}{*}{ Cyl. No. } & \multirow{2}{*}{ Type } & $2 \mathrm{r}$ & $\mathrm{t}$ & $\mathrm{Z}$ & \multicolumn{2}{|c|}{$\mathrm{P}_{\mathrm{CR}}$} \\
\cline { 6 - 7 } & & & & & Theory & Test \\
\hline 1 & Monocoque & 15.96 & 0.0200 & 1500 & 16000 & 10500 \\
3 & Monocoque & 15.76 & .0200 & 1500 & 16000 & 12300 \\
4 & Monocoque & 15.71 & .0200 & 1500 & 16000 & 8900 \\
5 & Inside rings & 15.79 & .0200 & 5.2 & 16000 & 15300 \\
6 & Inside rings & 15.76 & .0205 & 5.2 & 16800 & 14880 \\
7 & Inside rings & 15.76 & .0190 & 5.2 & 14400 & 15030 \\
8 & Outside rings & 15.77 & .0200 & 7.5 & 16000 & 15100 \\
9 & Outside rings & 15.78 & .0205 & 7.5 & 16800 & 16030 \\
& Outside rings & 15.76 & .0200 & 7.5 & 16000 & 15730 \\
\hline
\end{tabular}

$E=10.5 \cdot 10^{6} \mathrm{psi}$

$\nu=0.3$ 


\section{REFERENCES}

1. W. Nachbar and N. J. Hoff, "On the Edge Buckling of Axially Compressed Circular Cylindrical Shells," Quart. Appl. Math., Vol. XX, No. 3, Oct 1962, p. 267

2. M. Stein, The Influence of Prebuckling Deformations and Stresses on the Buckling of Perfect Cylinders, NASA TR R-190, 1964

3. G. Fischer, "Über den Einfluss der gelenkigen Lagerung auf die Stabilität dünnwandiger Kreiszylinderschalen unter Axiallast und Innendruck, "Z. Flugwiss., Jahrg. 11, Heft 3, Mär 1963, p. 111

4. H. Ohira, "Local Buckling Theory of Axially Compressed Cylinders," Proc. 11th Japan Natl. Congress for Appl. Mech., 1961

5. N. J. Hoff, "Low Buckling Stresses of Axially Compressed Circular Cylindrical Shells of Finite Length," Trans. ASME; J. Appl. Mech., Vol. 32, Series E, No. 3, Sep 1965, pp. 533-541

6. N. J. Hoff and L. W. Rehfield, "Buckling of Axially Compressed Circular Cylindrical Shells at Stresses Smaller Than the Classical Critical Value," Trans. ASME; J. Appl. Mech., Vol. 32, Series E, No. 3, Sept 1965, pp. 542-546

7. B. O. Almroth, Influence of Edge Conditions on the Stability of Axially Compressed Cylindrical Shells, NASA CR-161, Feb 1965

8. L. H. Donnell and C. C. Wan, "Effect of Imperfections on Buckling of Thin Cylinders and Columns Under Axial Compression," J. Appl. Mech., Vol. 17, No. 1, 1950

9. W. T. Koiter, "On the Stability of Elastic Equilibrium" (in Dutch with English summary), Thesis, Delft, H. J. Paris, Amsterdam (1945) 
10. Lockheed Missiles \& Space Company, The Effect of Axisymmetric Imperfections on the Buckling of Cylindrical Shells Under Axial Compression, by W. T. Koiter, 6-90-63-86, Sunnyvale, Calif., Aug 1963

11. C. D. Babcock and E. E. Sechler, "The Effect of Initial Imperfections on the Buckling Stress of Cylindrical Shells, " Collected Papers on Instability of Shell Structures, NASA TN D-1510 